\title{
Differential effects of diet- and genetically- induced brain insulin resistance on amyloid pathology in a mouse model of Alzheimer's disease
}

Tomoko Wakabayashi ${ }^{1,2+}$, Kazuki Yamaguchi ${ }^{1+}$, Kentaro Matsui ${ }^{1 \dagger}$, Toshiharu Sano ${ }^{1}$, Tetsuya Kubota ${ }^{3}$, Tadafumi Hashimoto ${ }^{1,2}$, Ayako Mano ${ }^{1}$, Kaoru Yamada', Yuko Matsuo ${ }^{1}$, Naoto Kubota ${ }^{4,5}$, Takashi Kadowaki ${ }^{4,6,7}$ and Takeshi Iwatsubo ${ }^{1 *}$ (D)

\begin{abstract}
Background: Based on epidemiological and experimental studies, type 2 diabetes mellitus (T2DM), especially insulin resistance that comprises the core mechanism of T2DM, has been recognized as a significant risk factor for Alzheimer's disease (AD). Studies in humans and diabetic AD model mice have indicated a correlation between insulin resistance and increased amyloid deposition in the brain. Paradoxically, mice with targeted disruption of genes involved in the insulin signaling pathway showed protective effects against the AD-related pathology. These conflicting observations raise an issue as to the relationship between dysregulation of insulin signaling and AD pathophysiology.

Methods: To study the causal relations and molecular mechanisms underlying insulin resistance-induced exacerbation of amyloid pathology, we investigated the chronological changes in the development of insulin resistance and amyloid pathology in two independent insulin-resistant AD mouse models, i.e., long-term high-fat diet (HFD) feeding and genetic disruption of Irs2, in combination with dietary interventions. In addition to biochemical and histopathological analyses, we examined the in vivo dynamics of brain amyloid- $\beta$ (A $\beta$ ) and insulin by microdialysis technique.
\end{abstract}

Results: HFD-fed diabetic AD model mice displayed a reduced brain response to peripheral insulin stimulation and a decreased brain to plasma ratio of insulin during the hyperinsulinemic clamp. Diet-induced defective insulin action in the brain was accompanied by a decreased clearance of the extracellular $A \beta$ in vivo and an exacerbation of brain amyloid pathology. These noxious effects of the HFD both on insulin sensitivity and on A $\beta$ deposition in brains were reversibly attenuated by dietary interventions. Importantly, HFD feeding accelerated A $\beta$ deposition also in the brains of IRS-2-deficient AD mice.

Conclusions: Our results suggested a causal and reversible association of brain A pathology by diet-dependent, but not genetically-induced, insulin-resistance. These observations raise the possibility that the causal factors of insulin resistance, e.g., metabolic stress or inflammation induced by HFD feeding, but not impaired insulin signaling per se, might be directly involved in the acceleration of amyloid pathology in the brain.

Keywords: Alzheimer's disease, Aß, Type 2 diabetes mellitus, Insulin resistance, Dietary intervention

\footnotetext{
* Correspondence: iwatsubo@m.u-tokyo.ac.jp

†Tomoko Wakabayashi, Kazuki Yamaguchi and Kentaro Matsui contributed equally to this work

'Department of Neuropathology, Graduate School of Medicine, The

University of Tokyo, 7-3-1 Hongo, Bunkyo-ku, Tokyo 113-0033, Japan

Full list of author information is available at the end of the article
}

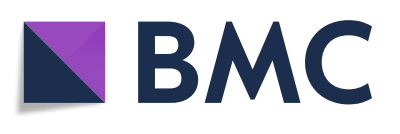

(c) The Author(s). 2019 Open Access This article is distributed under the terms of the Creative Commons Attribution 4.0 International License (http://creativecommons.org/licenses/by/4.0/), which permits unrestricted use, distribution, and reproduction in any medium, provided you give appropriate credit to the original author(s) and the source, provide a link to the Creative Commons license, and indicate if changes were made. The Creative Commons Public Domain Dedication waiver (http://creativecommons.org/publicdomain/zero/1.0/) applies to the data made available in this article, unless otherwise stated. 


\section{Background}

The numbers of patients with Alzheimer's disease (AD) and type 2 diabetes mellitus (T2DM) both have been steadily increasing, imposing a serious public health problem in aging societies. $\mathrm{AD}$ is the most common neurodegenerative disorder characterized by the progressive decline in memory and cognitive functions. Deposition of amyloid- $\beta$ peptides $(A \beta)$ as senile plaques in the brain is the hallmark pathology of AD, and it is now generally believed that multimerization and accumulation of $A \beta$ is a primary cause of neurodegeneration in AD brains [1]. In contrast to the rare, autosomal dominantly inherited early-onset $\mathrm{AD}$ that has demonstrated the pathogenic significance of $A \beta$, the vast majority of $\mathrm{AD}$ cases manifest as a sporadic form, where environmental and genetic factors may contribute to the pathophysiology of the disease. Among such factors, growing evidence suggests an association between T2DM and AD. A number of longitudinal epidemiological studies have shown that the incidence of $\mathrm{AD}$ is $~ 1.5$ - to 2-fold higher in patients with T2DM [2, 3].

T2DM is a complex metabolic disease characterized by defects in insulin action, progressive $\beta$-cell dysfunction and hyperglycemia. Although there are shared features between the pathophysiology underlying both diseases, the detailed molecular mechanism as to how T2DM increases the risk of AD remains to be solved [4]. Insulin resistance, the core component of T2DM, is developed in the early, pre-diabetes stage by a multifactorial process with environmental and genetic influences [5]. Recent studies have suggested that insulin resistance is also developed in the brains of $\mathrm{AD}$ patients, leading to the notion that insulin resistance is involved in the potential causal mechanism of AD [6-8].

Insulin resistance could influence the pathophysiology of $\mathrm{AD}$ in two possible manners. Insulin in the brain is thought to derive mainly from the periphery. In the central nervous system, insulin is involved in the regulation of the feeding behavior, whole body energy metabolism, as well as in memory and cognition by modulating synaptic function, neuronal survival, and neuronal glucose metabolism [9-11]. Patients with T2DM have been shown to develop cognitive dysfunction [12], in which dysregulation of brain insulin signaling is implicated. Recently, intranasal administration of insulin has shown to improve memory and cognitive functions in healthy elderly individuals as well as in patients with T2DM, mild cognitive impairment and AD [10, 13, 14]. Based on these observations, part of the cognitive deficits of AD due to T2DM could be attributed to the impaired brain insulin signaling [15].

The other important aspect connecting insulin resistance and the risk of $\mathrm{AD}$ is the effect on $\mathrm{AD}$-related neuropathology in the brain. Peripheral insulin resistance was shown to be associated with a higher risk of AD [16]. Furthermore, a histological study on postmortem brains of a large cohort Hisayama study revealed that insulin resistance was associated with an increased risk of senile plaque formation [17]. The association between insulin resistance and $A \beta$ accumulation in the brains of middle aged adults has also been shown by an amyloid PET neuroimaging study [18]. Studies using various experimental mouse models of AD support the observations in humans; induction of insulin resistance and related diabetic phenotypes by feeding a high-fat diet (HFD) increased A $\beta$ levels and amyloid deposition in the brains of AD model mice [19-21]. Collectively, insulin resistance either in the periphery or in brains appears to be correlated with the $A \beta$ accumulation.

A majority of previous studies in humans and research models suffered from limitations in unraveling the causal relations between the development of insulin resistance and the progression of amyloid pathology, because they have often been conducted in late stages of the disease where the AD pathology, especially the amyloid pathology has been fully developed. In considering the potential application of anti-diabetic therapeutic strategies on $\mathrm{AD}$, it is critical to determine whether T2DM-induced exacerbation of AD pathology would be a reversible process. Furthermore, the molecular mechanisms of "brain insulin resistance", which could either be due to impaired response of brain cells to the extracellular insulin or disrupted transport of blood insulin into the brain, have long remained unclear [22]. Notably, an in vivo examination of parenchymal insulin in relation to the metabolic abnormalities within brain areas affected in AD, e.g., hippocampus and cerebral cortex, has been lacking. It is also unknown how insulin resistance affects the brain $A \beta$ dynamics in vivo. Another important question arose from the observations in mice that lack genes encoding components of the insulin signaling pathway, which have suggested the protective effects of genetically reduced insulin signaling on amyloid deposition, cognitive function and survival of AD model mice [23-26]. These lines of paradoxical observations raised a question as to the consequences of reduced insulin signaling on $\mathrm{AD}$ pathophysiology.

To address these unresolved problems, we have investigated APP transgenic mice in two independent insulin-resistant conditions, i.e., HFD feeding and genetic disruption of insulin receptor substrate 2 (IRS-2). In these models, we have examined the precise chronological changes of the development of peripheral/central insulin resistance in relation to the brain amyloid dynamics in vivo. We also aimed to determine the relationship between the insulin-resistant states and amyloid pathology, by combining Irs 2 deletion and dietary interventions with $H F D$ feeding in the $A D$ model mice. Our 
results indicated the causal and reversible effects of diet-induced, but not genetically-induced, insulin resistance on brain $A \beta$ clearance and amyloid pathology. These observations raise the possibility that factors involved in the initiation of insulin resistance, e.g., metabolic stress induced by HFD-loading, but not impaired insulin signaling per se, might be directly involved in the induction of exacerbation of amyloid pathology in the brain.

\section{Methods}

\section{Animals}

A7 transgenic mice (A7- $\mathrm{Tg}$ ) overexpressing human APP695 harboring KM670/671NL and T714I familial AD mutations under the control of the Thy-1.2 promoter [27] were backcrossed and maintained on a C57BL/6J background. Irs $2^{-/-}$mice were generated as previously described [28]. Irs $2^{+/-}$mice were crossed with A7-Tg mice to generate $\operatorname{Irs} 2^{-/-}$;A7-Tg mice, and littermate controls were used. All experiments in this study were performed using male mice, unless otherwise stated. The animal care and experimental procedures were approved by the animal experiment committee of The University of Tokyo Graduate School of Medicine.

Mice were maintained on a $12 \mathrm{~h} \mathrm{light/dark}$ cycle and provided ad libitum access to water. During the feeding protocols, mice were fed a standard chow diet (CRF-1, Oriental Yeast Co., Ltd.) until 3 months of age. Then they were either maintained on the standard chow or were switched to a high-fat diet (HFD) containing 32\% fat (HFD32, CLEA Japan Inc.). For dietary intervention studies, groups of HFD-fed mice were switched back to the standard chow diet or caloric restriction (CR) at 9 months of age. A CR group was fed $70 \%$ of the food intake of the same genotype ad libitum controls.

\section{Metabolic measurements}

Plasma concentrations of insulin were measured using a mouse insulin ELISA kit (Morinaga Institute of Biological Science, Inc.). Blood glucose was measured using Glutest sensor (Sanwa Kagaku Kenkyusho Co., LTD.). For an insulin tolerance test (ITT), overnight-fasted mice were intraperitoneally injected with human insulin (Humulin R, Eli Lilly) at $0.75 \mathrm{U} / \mathrm{Kg}$ body weight, and blood glucose was measured at different time points.

\section{Protein extraction and Western blot analysis}

Brains were harvested, dissected into the hippocampus, cerebral cortex and hypothalamus, snap frozen in liquid nitrogen and stored at $-80^{\circ} \mathrm{C}$. For in vivo insulin stimulation experiments, 5-month-old mice were fasted for 4 $\mathrm{h}$ and intraperitoneally injected with $1 \mathrm{U}$ of human insulin or phosphate-buffered saline (PBS) pH 7.4 as a control. For analysis at 9 and 15 months of age, mice were fasted overnight and intraperitoneally injected with $5 \mathrm{U}$ of human insulin or PBS as a control. The mice were harvested after $40 \mathrm{~min}$.

Brain tissues were homogenized in a $1: 10(\mathrm{w} / \mathrm{v})$ volume of Tris-buffered saline (TBS), centrifuged at $260,000 \times \mathrm{g}$ for $20 \mathrm{~min}$ at $4{ }^{\circ} \mathrm{C}$ and supernatants were saved as TBS-soluble fractions. Resulting pellets were homogenized in a $1: 10(\mathrm{w} / \mathrm{v})$ volume of $2 \%$ Triton $\mathrm{X}-100$ in TBS and centrifuged at 260,000 $\mathrm{x}$ g for $20 \mathrm{~min}$ at $4{ }^{\circ} \mathrm{C}$. Pellets were then homogenized in a $1: 10(\mathrm{w} / \mathrm{v})$ volume of $2 \%$ SDS in TBS, incubated for $30 \mathrm{~min}$ at $37^{\circ} \mathrm{C}$ and centrifuged at $260,000 \times \mathrm{g}$ for $20 \mathrm{~min}$ at $20^{\circ} \mathrm{C}$. SDS-insoluble pellets were dissolved in $70 \%$ formic acid using a sonicator (Branson), centrifuged at $260,000 \mathrm{x} \mathrm{g}$ for $20 \mathrm{~min}$ at $4{ }^{\circ} \mathrm{C}$ and supernatants were desiccated by Speed-Vac followed by resuspension in DMSO. Protein concentration was determined with $\mathrm{BCA}$ protein assay kit (ThermoFisher). All the buffers contained cOmplete protease inhibitor and PhosSTOP phosphatase inhibitor cocktails (Merck).

For detection of phosphorylation of the insulin receptor (IR), Triton X-100 soluble fractions were incubated with anti-insulin receptor $\beta$ antibodies (C-19, Santa Cruz) overnight at $4{ }^{\circ} \mathrm{C}$. Protein $\mathrm{G}$ agarose beads (ThermoFisher) were added and incubated for $2 \mathrm{~h}$ at $4{ }^{\circ} \mathrm{C}$. The samples were washed three times with $2 \%$ Triton X-100 in TBS and eluted with Laemmli sample buffer containing 2\% 2-mercaptoethanol.

For immunoblotting, samples were separated by SDS-polyacrylamide gel electrophoresis under a reducing condition using a Tris-Tricine gel system, transferred to polyvinylidene difluoride membrane (Merck) and reacted with antibodies. The immunoblots were developed using ImmunoStar reagents (Wako) and visualized by LAS-4000 mini (Fujifilm). The antibodies and dilutions used in this study were: anti-insulin receptor $\beta$ C-19 (Santa Cruz) 1:2000, anti-phosphotyrosine 4G10 (Merck) 1:2000, anti-IDE ST1120 (Merck) 1:2000, anti- $\alpha$-tubulin DM1A (Merck) 1:10000.

\section{Immunohistochemical analysis and morphometry}

Mouse brains were fixed with $4 \%$ paraformaldehyde in PBS for $24 \mathrm{~h}$, dehydrated and embedded in paraffin. Serial sections were cut at $4-\mu \mathrm{m}$ thickness. Deparaffinized sections were treated with microwave $(700 \mathrm{~W})$ in citrate buffer pH 6.0 for $18 \mathrm{~min}$, followed by digestion with $100 \mu \mathrm{g} / \mathrm{ml}$ proteinase $\mathrm{K}$ (Worthington) in TBS for $6 \mathrm{~min}$ at $37^{\circ} \mathrm{C}$. After blocking by incubation with $10 \%$ calf serum in TBS, the sections were incubated with an anti-A $\beta$ antibody 82E1 (IBL) and then a biotinylated anti-mouse IgG antibody (Vector Laboratories), followed by visualization by avidin-biotin complex method (ABC elite, Vector Laboratories) using diaminobenzidine as chromogen. The sections were lightly counterstained with hematoxylin. The amyloid plaque burden of the 
indicated brain area was measured using Image $J$ software $(\mathrm{NIH})$ as previously described [29].

\section{In vivo microdialysis and glucose clamp}

For the analyses of interstitial fluid (ISF) insulin, mice were anesthetized and infusion catheters were inserted into the right jugular vein 2-3 days before the glucose clamp experiment. At the same time, microdialysis guide cannulas (AtmosLM, Eicom) were stereotaxically implanted into the left hippocampus (from bregma: -2.8 $\mathrm{mm} \mathrm{AP,} 0.5 \mathrm{~mm} \mathrm{ML},-1.3 \mathrm{~mm} \mathrm{DV}$ at $38^{\circ}$ angle) and fixed by dental cement. One day before clamps, AtmosLM probes with $1000 \mathrm{kDa}$ molecular weight cut-off (MWCO) membranes (Eicom) were inserted into the guide cannula and mice were placed into Raturn cage system (BASi). Artificial cerebrospinal fluid (aCSF; $1.3 \mathrm{mM} \mathrm{CaCl}_{2}, 1.2 \mathrm{mM} \mathrm{MgSO}_{4}-7 \mathrm{H}_{2} \mathrm{O}, 3.0 \mathrm{mM} \mathrm{KCl}, 0.4$ $\mathrm{mM} \mathrm{KH}_{2} \mathrm{PO}_{4}, 25 \mathrm{mM} \mathrm{NaHCO}_{3}$ and $122 \mathrm{mM} \mathrm{NaCl}$ ) containing $0.15 \%$ bovine serum albumin (BSA, Sigma) was perfused at $0.1 \mu \mathrm{l} / \mathrm{min}$. On the next day, insulin was continuously infused via the jugular line at the dose of 250 $\mathrm{mU} / \mathrm{kg} / \mathrm{min}$ for $10 \mathrm{~min}$ and $50 \mathrm{mU} / \mathrm{kg} / \mathrm{min}$ for $230 \mathrm{~min}$ (240 min in total). The blood glucose concentration was monitored every $10 \mathrm{~min}$ during the first $60 \mathrm{~min}$ and every $15 \mathrm{~min}$ afterwards by Glutest sensor via tail-tip bleeds. Based on that, glucose infusion rate (GIR, mg/ $\mathrm{kg} / \mathrm{min}$ ) was changed to maintain the blood glucose at approximately $60 \mathrm{mg} / \mathrm{dl}$ by the administration of $50 \%$ dextrose infusate (Otsuka) via the jugular line. The GIR was initially set at 60 and was adjusted accordingly. Blood samples were collected from the tail-tip at 0,30 , 60, 120, 180 and $240 \mathrm{~min}$, plasma insulin concentrations were measured by ELISA, and the average plasma insulin levels were determined. ISF was pooled throughout the 4-h clamp in one tube and the levels of insulin in the pooled ISF samples were determined by ultra-sensitive PLUS mouse insulin ELISA kit (Morinaga Institute of Biological Science, Inc.).

For the analyses of ISF A $\beta$, microdialysis guide cannulas (BASi) were implanted into the left hippocampus. Microdialysis probes with $30 \mathrm{kDa}$ MWCO membranes (BASi) were inserted and aCSF containing $0.15 \%$ BSA was perfused at $1 \mu \mathrm{l} / \mathrm{min}$. ISF samples were collected every $1 \mathrm{~h}$. To determine the half-life of ISF A $\beta$, compound $\mathrm{E}$ (Merck) was infused via reverse microdialysis for $6 \mathrm{~h}$ at $1 \mu \mathrm{M}$ after overnight collection of the baseline ISF. A $\beta$ half-life was determined as described previously [30].

\section{ELISA quantitation of $A \beta$}

To measure the A $\beta$ levels in ISF and brain soluble fractions, an equal volume of $1 \mathrm{M}$ guanidine hydrochloride was added and incubated for $30 \mathrm{~min}$ at room temperature. Levels of $A \beta$ were quantitated by BNT77/
BA27 or BNT77/BC05 Human/Rat $\beta$ Amyloid ELISA kit (Wako) [27].

\section{Acute brain slices}

Brains were removed and rapidly placed into chilled aCSF. The brain was cut by a razor blade coronally to remove the forebrain, brain stem and the cerebellum. The block was glued onto the vibratome stage and covered with chilled aCSF. Acute brain slices containing the hippocampus and cortex were made at $300 \mu \mathrm{m}$ intervals. During the cut, aCSF was bubbled with $95 \% \mathrm{O}_{2} / 5 \%$ $\mathrm{CO}_{2}$. Each slice was transferred on a cell strainer with a $100-\mu \mathrm{m}$ pore size mesh (ThermoFisher) within a chamber containing a medium (25\% inactivated horse serum, 0.5× MEM, 0.25× Hank's BSS, $5 \mathrm{mM}$ Tris and $26 \mathrm{mM}$ sodium bicarbonate) and placed in a tissue culture incubator. Cultured slices were homogenized in an equal amount of RIPA buffer (1\% NP-40, $0.5 \%$ sodium deoxycholate, $0.1 \%$ SDS in TBS) containing cOmplete protease inhibitor cocktail and centrifuged at 260,000 x g for 20 $\min$ at $4{ }^{\circ} \mathrm{C}$. $\mathrm{A} \beta$ levels in the culture media were measured using ELISA and adjusted by the protein content of each slice.

\section{Analysis of NEP activity}

Brain tissues were homogenized in a $1: 10(\mathrm{w} / \mathrm{v})$ volume of TBS and centrifuged at 260,000 x g for 20 min. The pellet was resuspended with $50 \mathrm{mM}$ Tris- $\mathrm{HCl} \mathrm{pH} 7.6$ by passing through a 27 -gauge syringe needle. Protein concentration was determined with BCA protein assay. The lysates were incubated with $\quad 50 \mu \mathrm{M} \quad 3$-dansyl-D-Ala-Gly-p-nitro-Phe-Gly (DAGNPG, Merck) and $1 \mu \mathrm{M}$ captopril in $50 \mathrm{mM}$ Tris- $\mathrm{HCl} \mathrm{pH} 7.6$ at $37^{\circ} \mathrm{C}$. After $2 \mathrm{~h}$ incubation, reactions were stopped by heating for $5 \mathrm{~min}$ at $100^{\circ} \mathrm{C}$ and the samples were centrifuged at $1000 \mathrm{x}$ g for $5 \mathrm{~min}$. The supernatant was diluted with $50 \mathrm{mM}$ Tris- $\mathrm{HCl}$ pH 7.6 and the fluorescence signals were measured using SpectraMax M2 (Molecular Devices) with the settings: excitation $342 \mathrm{~nm}$; emission $562 \mathrm{~nm}$.

\section{Quantitative reverse transcription PCR}

Total RNA was isolated using ISOGEN reagent (Nippon Gene). RNA purity and concentration were measured by Nanodrop (ThermoFisher). Total RNA was reverse-transcribed into cDNA using ReverTra Ace qPCR RT Master Mix with gDNA Remover (TOYOBO). Real-time PCR was performed using THUNDERBIRD SYBR qPCR Mix (TOYOBO) in LightCycler 450 system (Roche) in 384-well plates. Threshold cycle values were normalized to Gapdh. Primer pairs used in this study are as follows: 5'-AACGACCCCTTCAT TGAC-3' and 5'-GAAGACACCAGTAGACTCC AC-3' for Gapdh; 5'-GATTATGGCTCAGGGTCCA 
A-3' and 5'-GATTATGGCTCAGGGTCCAA-3' for TNF $\alpha$; 5'-AGTGGTGGCCACTAATGGAG-3' and 5' -CAATCCTTGCTTGATGCTGA-3' for Grp78/BiP; $5^{\prime}$-CCTAGCTTGGCTGACAGAGG-3' and $5^{\prime}$-CTGC TCCTTCTCCTTCATGC-3' for CHOP.

\section{Statistical analysis}

Quantitative data were analyzed statistically by two-tailed, unpaired t test for two-group data, one-way with repeated measures for data with multiple time points, or one-way or two-way ANOVA followed by post-hoc tests (as appropriate) for multiple group comparisons using GraphPad Prism 6. In figures, all data are represented by mean \pm SEM. Statistical significance is indicated by $* p<0.05,{ }^{* *} p<0.01$, and $* * * 0<0.001$.

\section{Results}

High-fat diet feeding led to obesity and peripheral insulin resistance in A7-Tg mice

Transgenic mice used in this study overexpress human APP harboring the Swedish and Austrian mutations under the control of the Thy-1.2 promoter (A7-Tg; [27]). A7-Tg mice develop progressive $A \beta$ deposition in brains starting at $\sim 12$ months of age. In this study, we focused on three different age ranges with distinct pathological stages of A7-Tg mice: 5 months of age when brain $A \beta$ is almost soluble, 9 months when the levels of both soluble and insoluble $\mathrm{A} \beta$ become gradually elevated with no visible amyloid plaques, and 15-18 months when amyloid plaques are massively accumulated. To investigate the effect of diet-induced obesity and insulin resistance on A $\beta$ pathology, we fed A7-Tg mice with a HFD starting from 3 months of age (Additional file 1: Figure S1a). At 3 months of age, no difference was found in the peripheral insulin sensitivity between A7-Tg and wild-type mice (Additional file 1: Figure S1b). After 6 months of treatment, 9-month-old HFD-fed male A7-Tg mice showed increases in body weight, fasting plasma insulin, fasting blood glucose, and reduced insulin sensitivity as measured by an insulin tolerance test (Fig. 1a-d). We also confirmed the effects of HFD feeding in female A7-Tg mice, which showed insulin resistance (Additional file 1: Figure S1c-g). These data suggest that ad libitum intake of the HFD induced metabolic dysregulation in A7-Tg mice.

\section{Impaired brain insulin response in HFD-fed A7-Tg mice}

Previous studies on animal models of diet-induced obesity have provided evidence that insulin resistance is induced in the hypothalamus, resulting in impaired regulation of whole-body energy expenditure [31]. However, it is not clear whether insulin resistance takes place in the whole brain. We investigated the relationship between HFD-induced $A \beta$ pathology and insulin signaling in the cerebral neocortices, where $\mathrm{AD}$ pathology is typically present in humans and model mice. Peripherally administered insulin stimulated tyrosine phosphorylation of the insulin receptor (IR) $\beta$-subunit in the cerebral cortices of A7-Tg mice (Fig. 1e). Intraperitoneal injection of $1 \mathrm{U}$ of insulin in 5-month-old A7-Tg mice showed that insulin-dependent phosphorylation of IR in the brain was significantly suppressed by HFD feeding (Fig. 1e). Nine-month-old A7-Tg mice were also examined by injecting $5 \mathrm{U}$ of insulin, in which the levels of elevated plasma insulin were comparable between control and HFD mice $(11.58 \pm 1.75$ vs $10.51 \pm 1.29 \mu \mathrm{g} / \mathrm{ml}$, not significant). When the extent of phospho-IR was compared between PBS- and insulin-treated groups, HFD-fed A7-Tg mice showed a higher rate of change compared with the control mice (Fig. 1f). This might be due to the differential effect of HFD feeding on the basal levels, and acute response to insulin, of phosphorylation of IR in the brain. However, the absolute levels of both steady state and insulin-induced phospho-IR were significantly reduced in the HFD group compared with the control (Fig. 1f). The levels of insulin-dependent tyrosine phosphorylation of IGF-1R and IRS-2 were also lower in HFD-fed A7 brains, although the difference between chow and HFD-fed groups was not statistically significant (Additional file 1: Figure S1 h and i). Altogether, these observations suggest that brain response to peripheral insulin stimulation was impaired at as early as 5 months of age.

\section{Reduced ISF/plasma insulin ratio during the hyperinsulinemic glucose clamp in HFD-fed A7-Tg mice}

Although the mechanisms underlying the brain insulin resistance are not fully elucidated, it is speculated to result either from impaired response in neuronal insulin signaling or reduced blood-to-brain transport of insulin, or both [22]. Our in vivo insulin stimulation analysis demonstrated reduced kinase activation of IR, an immediate target of insulin, in the brains of HFD-fed A7-Tg mice, which led us to examine if the levels of brain interstitial insulin are reduced. To directly assess the effect of HFD-induced metabolic abnormalities on delivery of insulin across the vascular barrier and central insulin levels, we performed hyperinsulinemic glucose clamps combined with in vivo brain microdialysis using 1000 $\mathrm{kDa}$ molecular weight cut-off (MWCO) probes [32]. Insulin was infused via the jugular line, while blood glucose levels were maintained constant by administrating dextrose through the jugular line (Fig. 1g). During the 4-h clamps, plasma insulin levels were elevated and not different between the control and HFD-fed groups (Fig. 1h). We then measured the insulin levels in the brain interstitial fluid (ISF), which were 0.304 \pm 0.061 and $0.220 \pm 0.055 \mathrm{ng} / \mathrm{ml}$ in chow and HFD-fed 


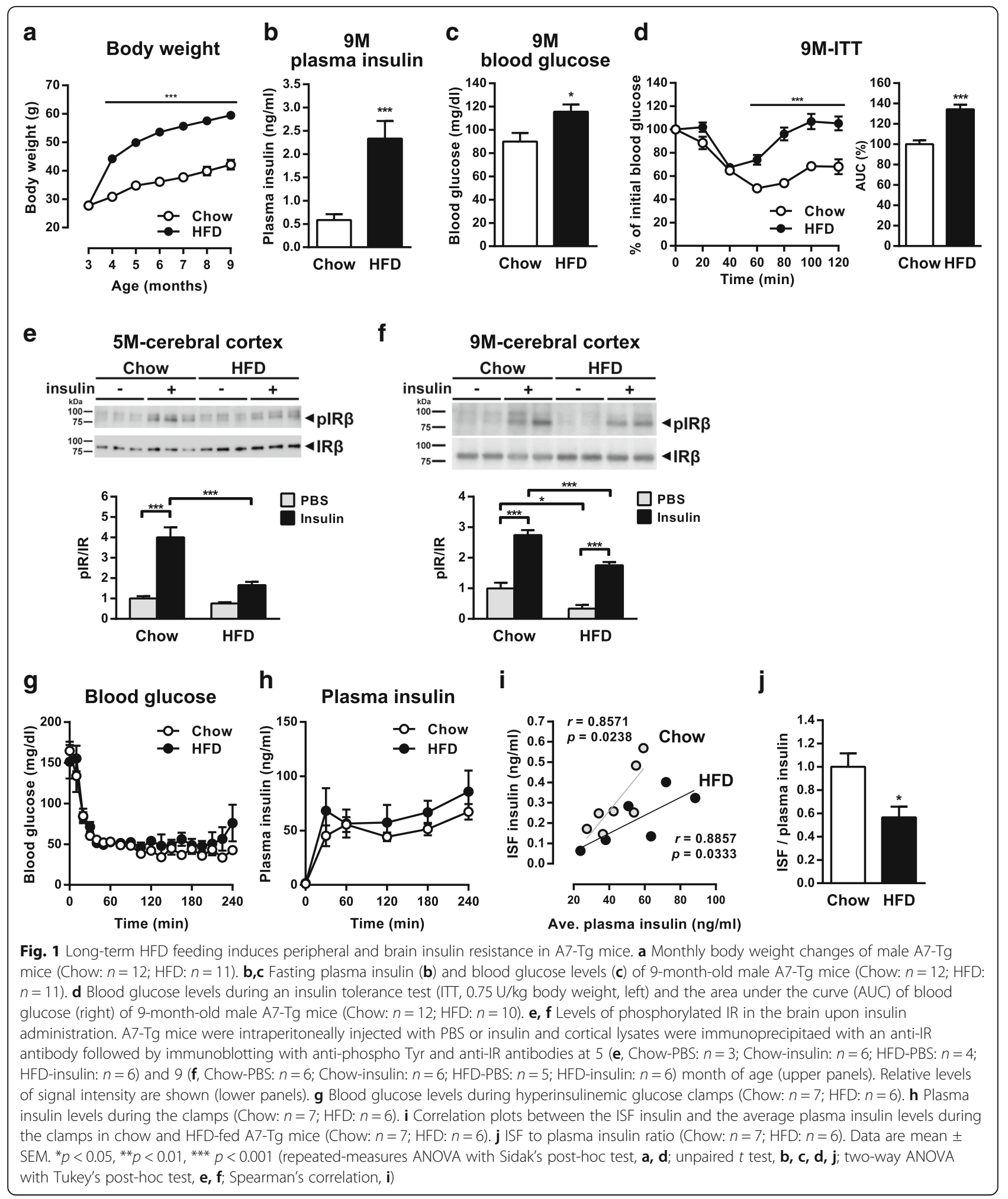

A7-Tg mice, respectively. The levels of basal ISF insulin were not detectable in our study. Although the levels of ISF insulin during the clamp were considerably lower than that of plasma insulin, these were positively and significantly correlated with the average concentrations of plasma insulin both in chow-fed $(r=0.8571, p=0.0238)$ and HFD-fed $(r=0.8857, p=$ 0.0333) A7-Tg mice (Fig. 1i). When the ratios of ISF 
insulin to the average plasma insulin levels were compared between the control and HFD groups, HFD-fed A7-Tg mice showed a significantly lower ISF/plasma ratio (Fig. 1j). These results raised the possibility that the transport of exogenously administrated insulin to the brain was impaired by HFD feeding in $\mathrm{A} 7-\mathrm{Tg}$ mice.

\section{Insulin resistance precedes HFD-induced exacerbation of $A \beta$ deposition in the brains of A7-Tg mice}

To investigate the relationship between the HFD-induced impairment in insulin signaling and the amyloid pathology, we examined the longitudinal changes in $A \beta$ pathology in the brains of HFD-fed A7-Tg mice. First, we biochemically investigated the chronological relation between the HFD-induced impaired insulin signaling and the $A \beta$ deposition. Two-month feeding on the HFD, which significantly suppressed insulin responses in brains (Fig. 1e), had no effect on the levels of $A \beta 40$ and $A \beta 42$ in TBS-soluble extracts of the cerebral cortices of 5-month-old A7-Tg mice yet (Fig. 2a). At 9 months of age, i.e., prior to plaque deposition, HFD feeding already led to an increase in cerebral $A \beta 40$ and $A \beta 42$ levels both in TBS-soluble and TBS/Triton X-100/SDS-insoluble fractions (Fig. 2b). There also was a significant increase in the levels of $\mathrm{A} \beta 42$ in the hippocampus of HFD-fed A7-Tg mice, where amyloid deposition occurs slightly later than in cortices in A7-Tg mice (Additional file 2: Figure S2). At 15 months of age, the concentrations of both soluble and insoluble $A \beta$ in the brain were increased in proportion to the deposition of amyloid plaques, and HFD feeding further increased the levels of insoluble $A \beta 42$ in the neocortices of A7-Tg mice (Fig. 2c).

Consistent with earlier studies in other AD mouse models [19-21], A $\beta$ deposition was significantly enhanced by HFD feeding in the neocortices as well as hippocampus of aged A7-Tg mice (Fig. 2d-g). Quantification of percentage areas covered by $\mathrm{A} \beta$ immunoreactivity showed a $\sim 2$-fold increase in amyloid deposition in HFD-fed mice. These results revealed that the HFD-induced impairments in insulin signaling both in peripheral tissues and brains precede the increase in $A \beta$ levels in the brains of $\mathrm{A} 7-\mathrm{Tg}$ mice.

\section{Decreased clearance of ISF A $\beta$ in HFD-fed A7-Tg mice}

The levels of $A \beta$ in the brain are regulated by a balance between production, clearance and aggregation. We therefore examined which step(s) of $A \beta$ dynamics may account for the exacerbation of amyloid pathology in the HFD-fed A7-Tg brains. Immunoblot analysis of APP, C-terminal fragments (CTFs) of APP, $\beta$-secretase (BACE1) and $\alpha$-secretase (ADAM10) showed no significant differences between the cerebral cortex of 5-month-old control and HFD-fed A7-Tg mice
(Additional file 3: Figure S3a). At 9 months of age, the levels of CTF $\alpha$ and CTF $\beta$ in HFD-fed mice were slightly higher than that of the control group (Additional file 3: Figure S3b), which could be due to either altered APP processing by $\alpha$ - and $\beta$-secretases or decreased clearance of the APP fragments. To evaluate the effects of HFD on amyloidogenic APP processing, we measured the amount of $A \beta$ released from acute brain slices of $A 7-T g$ mice. Levels of $A \beta 40$ and $A \beta 42$ in the media of 10-month-old HFD-fed A7-Tg brain slice were not different from that of control brain slice (Fig. 3a), and neither of the levels of total sAPP, sAPP $\alpha$ nor SAPP $\beta$ were altered in the media of HFD-fed mouse slice cultures (Additional file 3: Figure S3c). These results suggest that increased $A \beta$ production may not be responsible for the incremental effect of HFD on $A \beta$ deposition.

Several studies have shown that HFD feeding affects the expression levels and/or activities of $\mathrm{A} \beta$ degrading enzymes, i.e., insulin degrading enzyme (IDE) and neprilysin (NEP) $[19,33,34]$. In our model, however, we did not find any effects of HFD feeding on IDE levels or neprilysin activity in the brains of 9-month-old A7-Tg mice (Fig. 3b and c).

Since no in vivo study has so far investigated the effect of diet-induced metabolic abnormalities on the brain $\mathrm{A} \beta$ metabolism, we examined the levels and half-life $\left(t_{1 / 2}\right)$ of $\mathrm{A} \beta$ in the brain ISF by using in vivo microdialysis technique. To measure ISF $A \beta$, mice were implanted with microdialysis probes with $30 \mathrm{kDa}$ MWCO in the hippocampus and ISF was collected every $60 \mathrm{~min}$ [30]. Baseline levels of ISF $\mathrm{A} \beta 42$ were similar between chow and HFD-fed A7-Tg mice at 5 months of age (Fig. $3 \mathrm{~d}$ and e). The $t_{1 / 2}$ of ISF $\mathrm{A} \beta 42$ was then determined by administering a potent $\gamma$-secretase inhibitor compound $E$ locally through reverse dialysis. Following compound $\mathrm{E}$ infusion, ISF A 442 levels were rapidly decreased by $\sim 60 \%$ compared to the baseline (Fig. 3d). A semi-log plot of concentration versus time suggested first-order kinetics for ISF A 342 (Fig. 3f). The $t_{1 / 2}$ calculated based on the slope of decline in the levels of ISF A $\beta 42$ was comparable between the control and HFD-fed groups at 5 months of age $(2.52 \pm 0.370 \mathrm{~h}$ and $2.38 \pm 0.274 \mathrm{~h}$, respectively, Fig. 3g). In 9-month-old A7-Tg mice, baseline levels of ISF A $\beta 42$ were also not significantly different between the control and HFD-fed A7-Tg mice (Fig. $3 \mathrm{~h}$ and i). Interestingly, however, elimination of ISF $\mathrm{A} \beta 42$ after compound $\mathrm{E}$ treatment was markedly delayed by HFD feeding. Analysis of the $t_{1 / 2}$ for ISF $\mathrm{A} \beta 42$ was $1.69 \pm 0.176 \mathrm{~h}$ in the control mice and $2.82 \pm 0.254 \mathrm{~h}$ in HFD-fed mice, showing a significant difference between the two groups $(p=0.0026$, Fig. $3 j$ and $k$ ). Together, these observations suggest that the reduced clearance of $A \beta$ might be involved in the HFD-induced exacerbation of $A \beta$ pathology. 

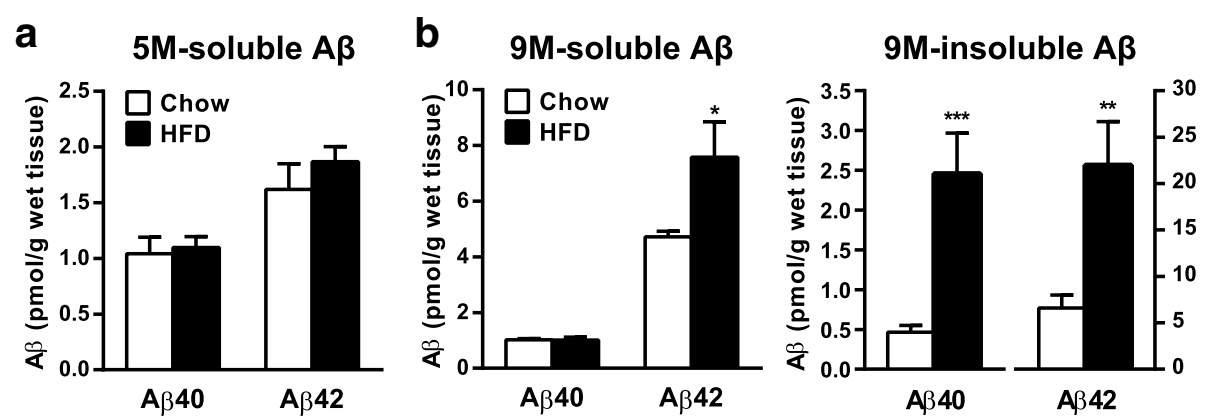

C

$15 \mathrm{M}$-soluble $A \beta$

$15 \mathrm{M}$-insoluble $A \beta$
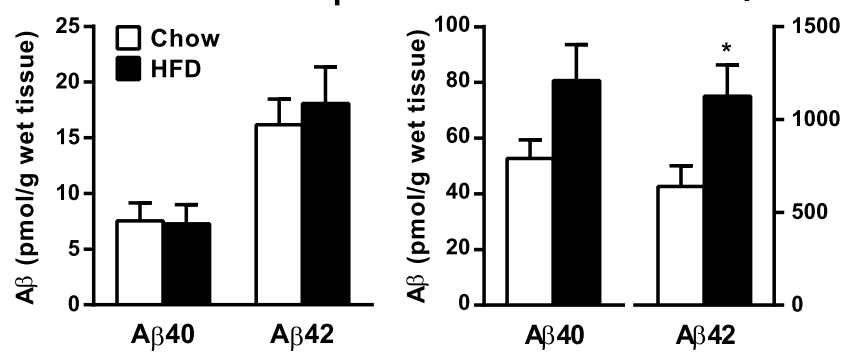

d

15M-cerebral cortex

e

15M-hippocampus
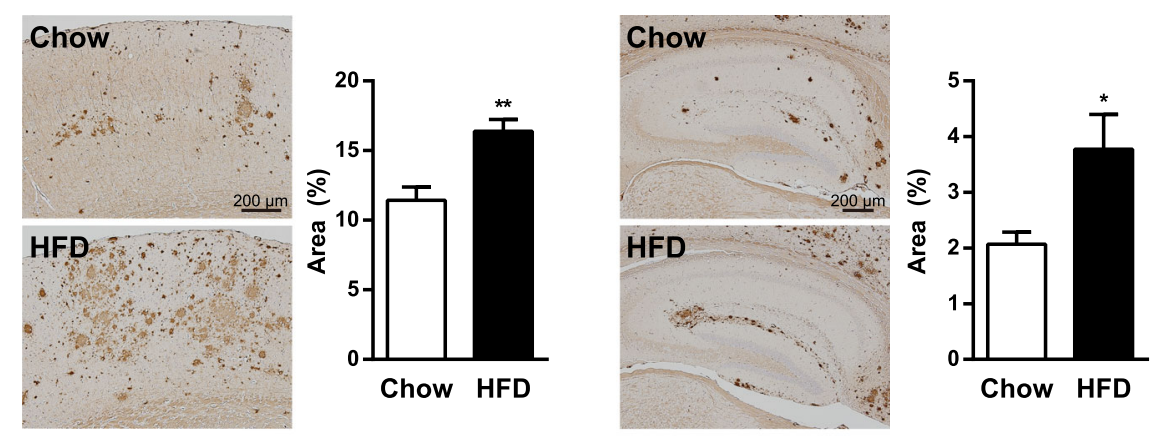

f

18M-cerebral cortex

g
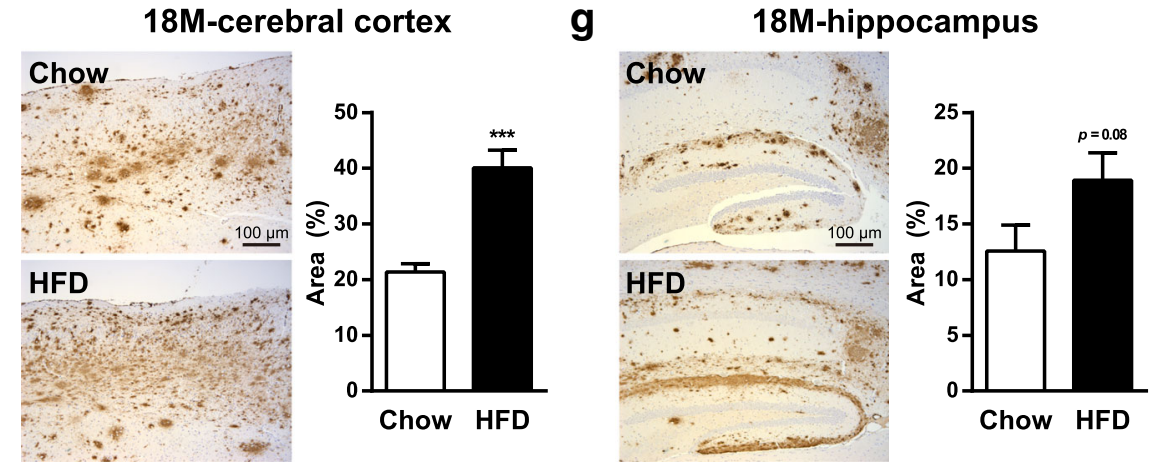

Fig. 2 Development of insulin resistance precedes HFD-induced exacerbation of A $\beta$ deposition in A7-Tg mouse brains. a Soluble A 340 and $A \beta 42$ levels in the cerebral cortex of 5-month-old male A7-Tg mice fed with chow $(n=9)$ or HFD $(n=10)$. b Soluble (left) and insoluble (right) A 40 and AB42 levels in the cerebral cortex of 9-month-old male A7-Tg mice fed with chow $(n=12)$ or HFD $(n=11)$. c Soluble (left) and insoluble (right) $A \beta 40$ and A 442 levels in the cerebral cortex of 15-month-old female A7-Tg mice fed with chow $(n=5)$ or HFD $(n=6)$. d-g Immunohistochemical analysis of female A7-Tg mouse brains using an anti-A $\beta$ (82E1) antibody. Representative images of the cerebral neocortex at the level of hippocampus (d), hippocampus (e) and the percentage area covered by $A \beta$ immunoreactivity (right panels in each figure) from 15-month-old A7-Tg mice fed with chow $(n=5)$ or HFD $(n=6)$. Data from the cerebral neocortex (f) and hippocampus $(\mathbf{g})$ of 18 -month old A7-Tg mice fed with chow $(n=9)$ or HFD $(n=7)$ also are shown. Data are mean \pm SEM. ${ }^{*} p<$ $0.05,{ }^{* *} p<0.01,{ }^{* * *} p<0.001$ (unpaired $t$ test) 


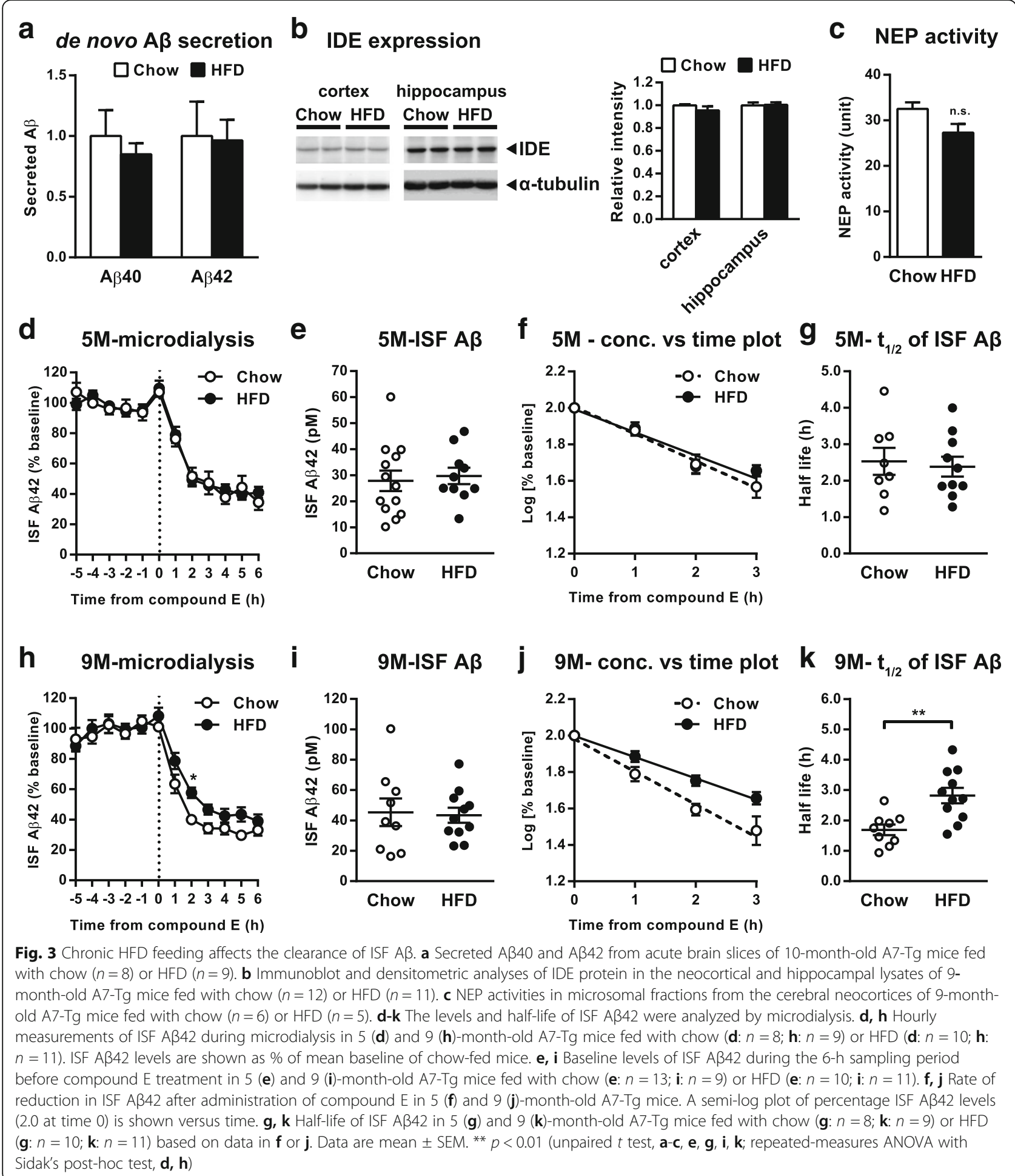

Dietary interventions reverse HFD-induced metabolic impairments and accelerated $A \beta$ pathology in A7-Tg mice Next, we aimed to examine if an improvement in insulin resistance could reverse the exacerbating effects of HFD on $\mathrm{A} \beta$ pathology. To test this, we employed dietary interventions, which have been shown to rescue metabolic deficiencies caused by the HFD [35]. In the A7-Tg mouse model, we first verified beneficial effects of $30 \%$ caloric restriction (CR) on the metabolic parameters. CR suppressed body weight gain, and increased both peripheral and central insulin sensitivity (Additional file 4: Figure S4a-d). 
In our experimental settings, the effect of HFD-induced metabolic dysregulation on amyloid pathology was evident by 9 months of age. Thus, we switched the feeding of 9-months-old HFD-fed A7-Tg male mice to a regular chow or a regular chow with $30 \% \mathrm{CR}$ (referred to as HFD-Chow or HFD-CR, respectively, Fig. 4a). After switching to the chow diet or $\mathrm{CR}$, body weight was rapidly decreased within 2-3 months and remained stable afterwards (Fig. 4b). At the end of the experiments, the average body weight was very similar between HFD-Chow (48.2 \pm $3.3 \mathrm{~g}$, Fig. $4 \mathrm{~b})$ and the chow-fed control mice $(44.6 \pm 3.5 \mathrm{~g}$, Additional file 4: Figure S4a), or between HFD-CR (27.4 \pm 0.2 g, Fig. $4 \mathrm{~b})$ and CR mice (26.5 $\pm 0.3 \mathrm{~g}$, Additional file 4 : Figure S4a). Although the levels of fasting plasma insulin were not altered between HFD-Chow, HFD-CR and HFD groups (Fig. 4c), fasting blood glucose levels were significantly lower in 15-month-old HFD-CR mice (Fig. 4d) below those observed in $\mathrm{CR}$ and the chow control mice (Additional file 4: Figure S4b). The insulin tolerance test at 15 months of age demonstrated that HFD-induced insulin resistance was improved in both HFD-Chow and HFD-CR mice (Fig. 4e). The changes in blood glucose levels during the tests in HFD-Chow $(\sim 60 \%$ reduction at $60 \mathrm{~min})$ and HFD-CR mice $(\sim 75 \%$ reduction at $60 \mathrm{~min}$, Fig. 4e) were similar to those of mice continuously fed with each diet (Additional file 4: Figure S4c). We also examined brain insulin response to peripherally administered insulin. HFD-CR mice showed significantly increased IR phosphorylation in response to insulin, whereas HFD-Chow mice showed slightly improved response that was not significant compared to that of HFD-fed A7-Tg mice (Fig. 4f). These results indicated that dietary interventions improved both peripheral and central insulin signaling corresponding to the degree of diet restriction.

We next examined whether the rescue of metabolic abnormalities was associated with a reversal of HFD-induced exacerbation of amyloid pathology in A7-Tg mice. Immunohistochemical analysis showed that $C R$ dramatically attenuated $A \beta$ deposition in the brains of A7-Tg mice (Fig. $4 \mathrm{~g}$ and $\mathrm{h}$ ), consistent with the previously reported results in other APP transgenic mouse models [36, 37]. Notably, the dietary interventions significantly ameliorated $A \beta$ pathology in the cerebral cortices of 15-month-old A7-Tg mice to the same extent as the chow-fed control mice (Fig. 4g). The protective effect of dietary intervention was also observed in the brains of 18-month-old HFD-CR mice (Fig. 4h). These results demonstrated that controlling diet can reverse the deteriorating effect of HFD on brain amyloid pathology even after HFD-induced elevation of $\mathrm{A} \beta$ levels has been initiated. Altogether, changing the states of the peripheral and brain insulin signaling in either way was correlatively associated with the brain $A \beta$ metabolism.

\section{Deletion of IRS-2 induces metabolic impairments and suppresses $A \beta$ accumulation in $A 7-T g$ mice}

Correlation between diet-induced metabolic phenotypes and modulation of $\mathrm{A} \beta$ pathology in $\mathrm{A} 7-\mathrm{Tg}$ mice raised a question as to what pathophysiological factor(s) of the metabolic syndrome, e.g. hyperinsulinemia, hyperglycemia, insulin resistance, are responsible for the induction of amyloid pathology. To address this issue, we next employed another diabetic mouse model that genetically lacks IRS-2. The mice deficient in IRS-2 have been shown to display T2DM-like phenotypes due to insulin resistance of the liver and defective pancreatic $\beta$-cell function [28]. Previous studies using $\operatorname{Tg} 2576$ APP transgenic mice crossed with Irs 2 knockout mice suggested a protective effect of IRS-2 disruption on $A \beta$ pathology [23, 24]. To further examine the underlying mechanisms, we generated $\operatorname{Irs} 2^{-1-}$;A7-Tg mice.

Irs ${ }^{-/-}$;A7-Tg mice displayed a slight increase in body weight and elevated fasting blood glucose at 5 and 9 months of age, indicating development of T2DM-like metabolic defects (Fig. 5a and b). The levels of fasting plasma insulin were also higher in 9-month-old $\operatorname{Irs} 2^{-1}$ ${ }^{-}$;A7-Tg mice (Fig. 5c). Biochemical analysis showed significantly lower levels of $A \beta 40$ and $A \beta 42$ both in soluble and insoluble cerebral fractions of 9-month-old $\operatorname{Irs} 2^{-\prime}$ ${ }^{-}$;A7-Tg mice compared to those of $\operatorname{Irs} 2^{+/+}$;A7-Tg mice (Fig. 5d). In aged 15-month-old A7-Tg mice, the lack of IRS-2 significantly suppressed amyloid deposition in the cerebral cortex (Fig. 5e). These observations were in agreement with previous studies in which genetically induced impairment of insulin signaling significantly suppressed $A \beta$ deposition in Alzheimer model mice [23, 24].

Given that the physiological consequences of increases in body weight, blood glucose, blood insulin and reduced insulin signaling on amyloid deposition were opposite between the models of HFD-induced insulin resistance and genetic disruption of the insulin signaling pathway, we sought to clarify the difference between the two diabetic models. To this end, we investigated the systemic inflammation and the endoplasmic reticulum (ER) stress, which have been implicated in the development of insulin resistance and T2DM [38]. mRNA levels of inflammatory cytokine TNFo and ER stress-related genes such as Grp78/BiP and CHOP in adipose tissue were significantly elevated by HFD feeding in $\operatorname{Irs} 2^{+/+} ; \mathrm{A} 7-\mathrm{Tg}$ mice, as expected (Additional file 5: Figure S5). In contrast, adipose tissue of $\operatorname{Irs}^{-/-}$;A7-Tg did not show elevated expression of the genes despite the peripheral insulin resistance and diabetic phenotypes (Additional file 5: Figure S5). These results indicated that diet-induced obesity and metabolic stress might be one of the exacerbating factors of AD-like pathology. 


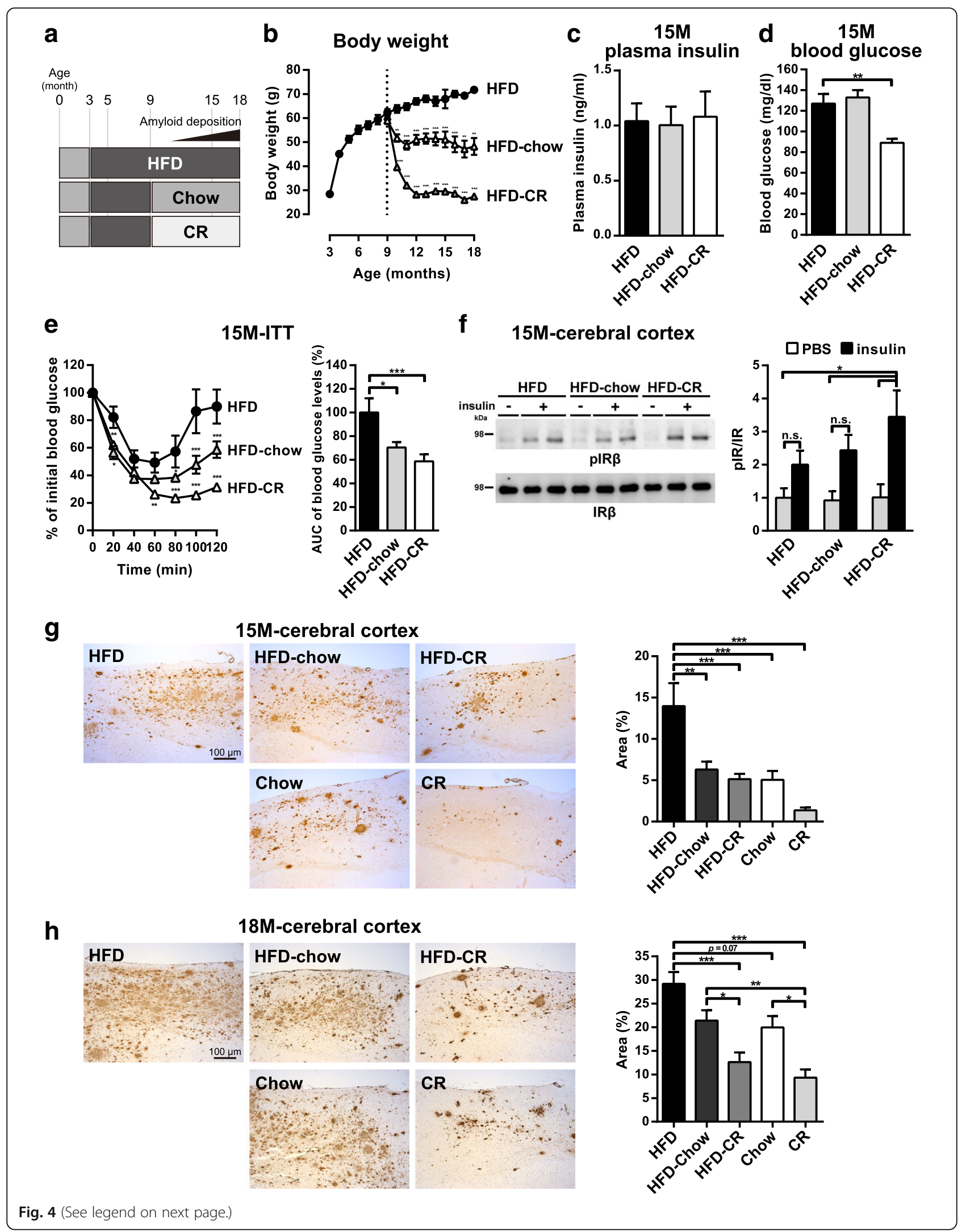


(See figure on previous page.)

Fig. 4 Dietary interventions ameliorate HFD-induced metabolic impairments and A $\beta$ pathology in A7-Tg mice. a Experimental scheme. Male A7-Tg mice were fed with HFD for 6 months, followed either by the chow diet (HFD-Chow), 30\% calorie-restricted diet (HFD-CR) or remained on HFD for 9 months. b Monthly body weight changes of A7-Tg mice fed with HFD-Chow, HFD-CR or HFD ( $n=12$ per group). c Fasting plasma insulin levels of 15month-old A7-Tg mice fed with HFD $(n=10)$, HFD-Chow $(n=11)$ or HFD-CR $(n=11)$. d Fasting blood glucose levels of 15-month-old A7-Tg mice fed with HFD $(n=8)$, HFD-Chow $(n=10)$ or HFD-CR $(n=11)$. e Blood glucose levels of 15-month-old A7-Tg mice fed with HFD $(n=8)$, HFD-Chow $(n=9)$ or HFD-CR ( $n=11)$ during the ITT (left) and the AUC of blood glucose (right). $\mathbf{f}$ Immunoblot (left) and densitometric (right) analyses of phosphorylated/ total IR levels in the cortices of 15-month-old A7-Tg mice fed with HFD ( $n=6$ and 4), HFD-Chow ( $n=6$ and 5) or HFD-CR $(n=5$ and 6$)$ treated with PBS or

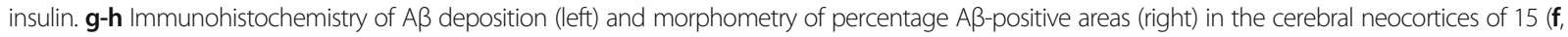
HFD: $n=10$; HFD-Chow: $n=10$; HFD-CR: $n=11$; Chow: $n=10 ;$ CR: $n=11$ ) and 18 (g, HFD: $n=7$; HFD-Chow: $n=12 ;$ HFD-CR: $n=12 ;$ Chow: $n=9$; CR: $n=$ 10)-month-old A7-Tg mice. Data are mean \pm SEM. ${ }^{*} p<0.05,{ }^{* *} p<0.01,{ }^{* * *} p<0.001$ (repeated-measures ANOVA with Sidak's post-hoc test, $\mathbf{b}$, e; one-way ANOVA with Dunnett's post-hoc test, $\mathbf{c}, \mathbf{d}$, e; two-way ANOVA with Tukey's post-hoc test, $\mathbf{f}$; one-way ANOVA with Tukey's post-hoc test, $\mathbf{g}$, $\mathbf{h}$ )

HFD feeding on IRS-2-deficient A7-Tg mice exacerbated diabetic phenotype as well as $A \beta$ pathology

Based on the results from the two diabetic AD mouse models, we further examined the association between impaired insulin signaling, metabolic stress and $A \beta$ pathology by feeding Irs $2^{-/}$;A7-Tg mice with HFD. During the 6 months of HFD feeding, male $\operatorname{Irs} 2^{-/} ; \mathrm{A} 7-\mathrm{Tg}$ mice gained more weight than chow-fed controls (Fig. 6a). These mice also exhibited chronically higher levels of blood glucose (Fig. 6b). After 6 months of HFD feeding, 9-month-old Irs $2^{-1-}$;A7-Tg mice exhibited increases in plasma insulin levels and insulin resistance, indicating the HFD-induced aggravation of metabolic abnormalities (Fig. 6c and d). Twelve months of HFD feeding caused a significant
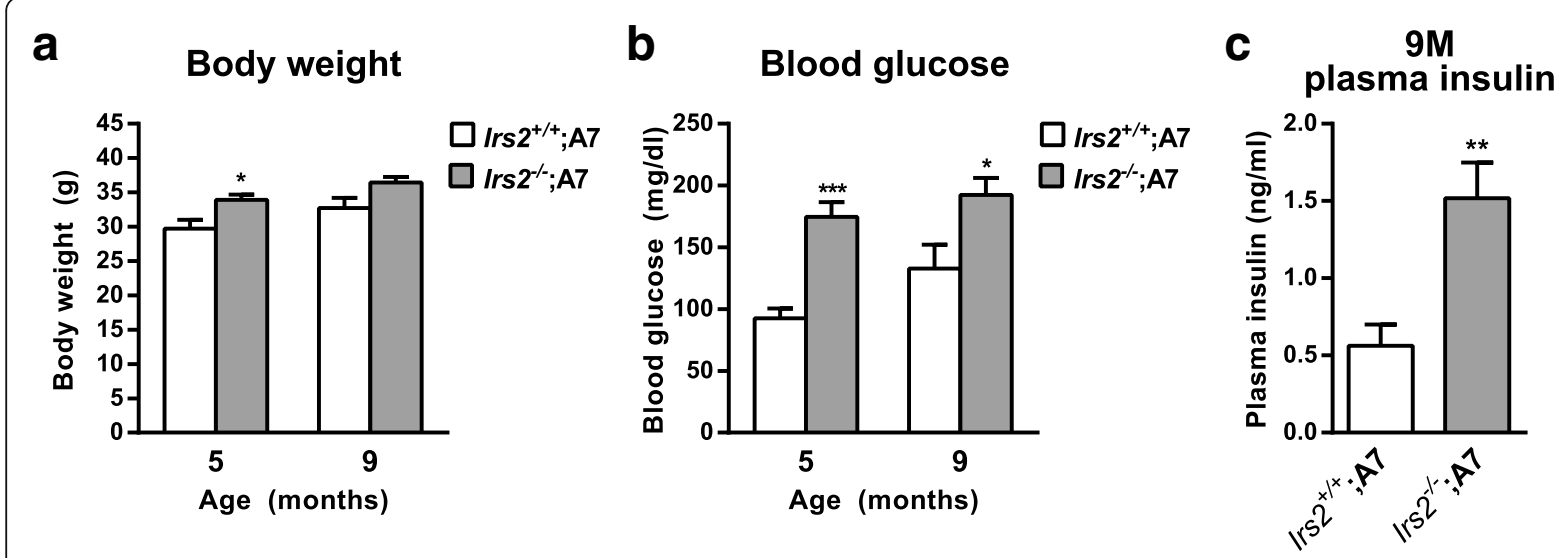

d

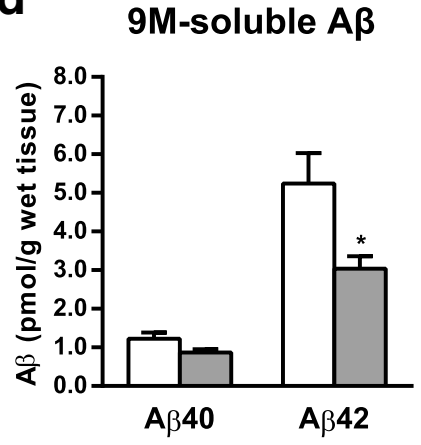

9M-insoluble $A \beta$

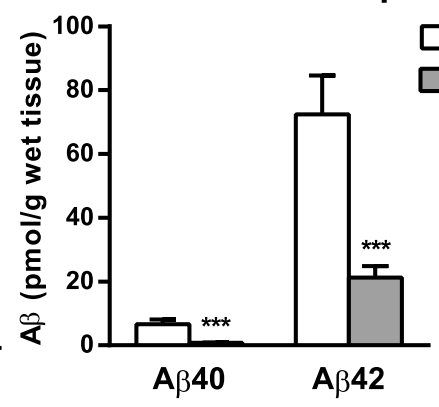

e
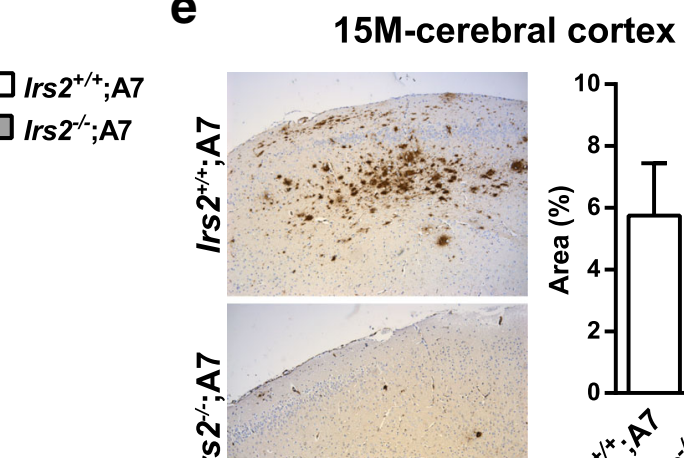
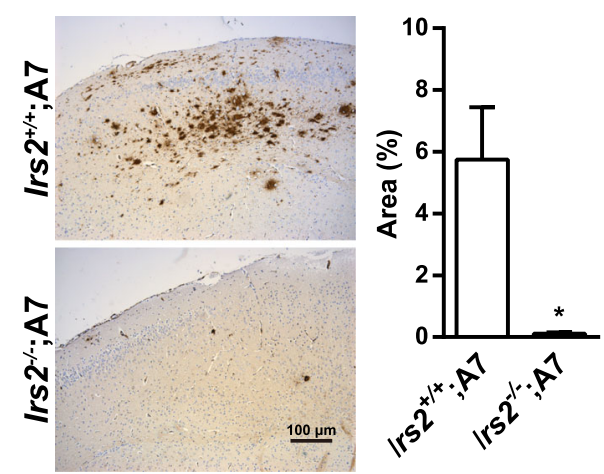

Fig. 5 Deletion of IRS-2 induces metabolic impairments but suppresses A 3 deposition in A7-Tg mice. a Body weight of IRS-2-deficient A7-Tg mice at 5 and 9 month of age (Irs2 ${ }^{+++} ; A 7-T g$ mice: $n=6 ;$ Irs $2^{-1-}$;A7-Tg mice: $\left.n=5\right)$. b Fasting blood glucose levels of 5 and 9-month-old IRS-2-deficient A7-Tg

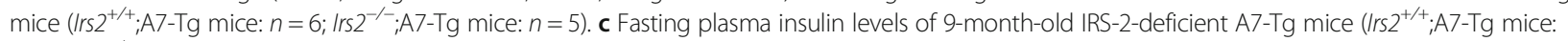
$n=6 ;$ Irs2 ${ }^{-1-} ; A 7-T g$ mice: $n=5$ ). d Soluble (left) and insoluble (right) A 340 and A 342 levels in the cerebral neocortices of 9-month-old IRS-2-deficient

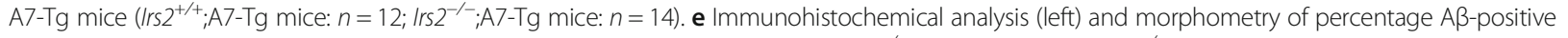
areas (right) of cerebral neocortices of 15-month-old IRS-2-deficient A7-Tg mice (Irs2 ${ }^{+/+} ; A 7-T g$ mice: $n=3 ; \operatorname{Irs} 2^{-1-} ;$ A7-Tg mice: $\left.n=4\right)$. Data are mean \pm SEM. ${ }^{*} p<0.05,{ }^{* * *} p<0.001$ (unpaired $t$ test) 


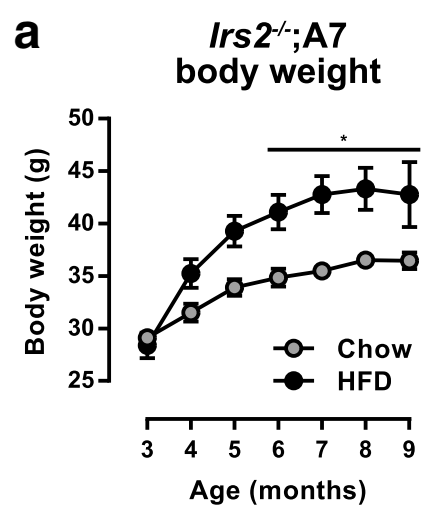

d
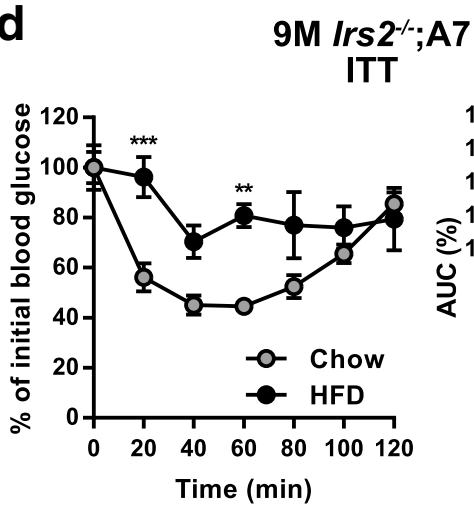

f
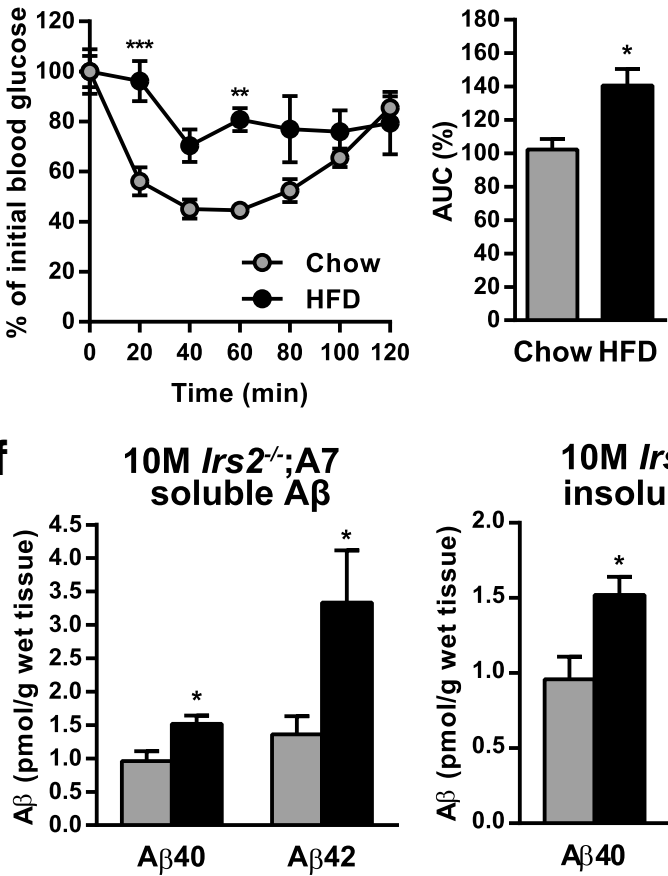

$10 \mathrm{M}$ Irs 2--;A7 insoluble $A \beta$

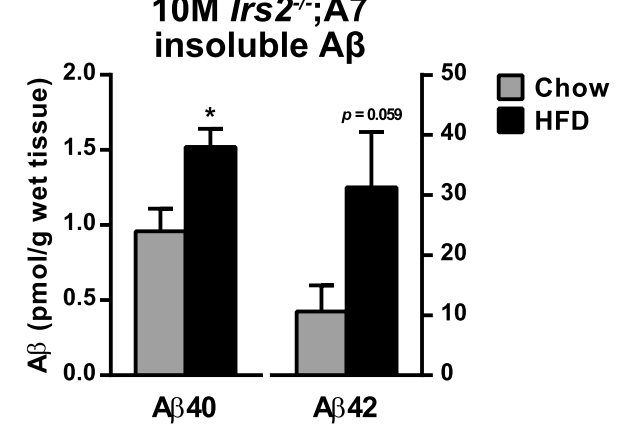

g

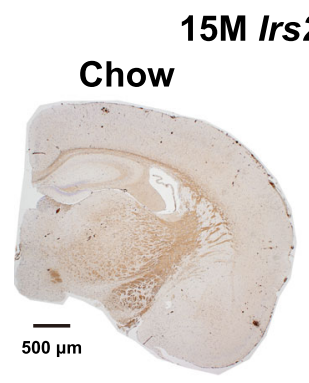

b Irs2-;A7 blood glucose

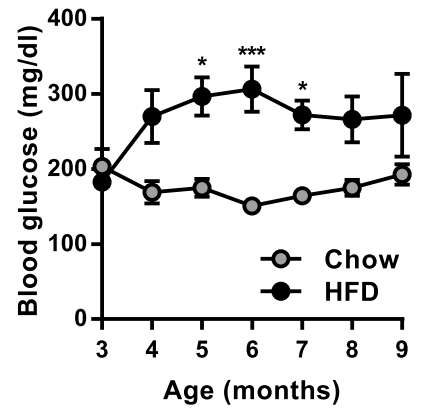

e
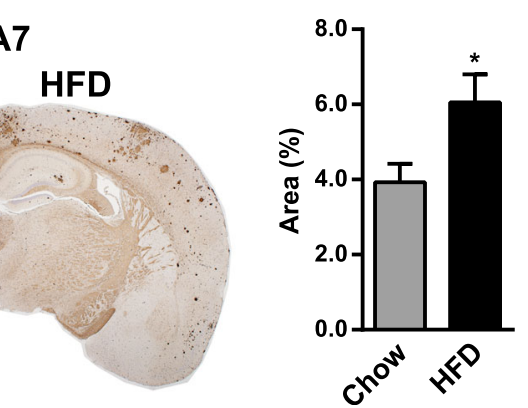

C $\quad \begin{gathered}9 \mathrm{M} \text { Irs } 2^{-/ ;} ; \mathrm{A} 7 \\ \text { plasma insulin }\end{gathered}$

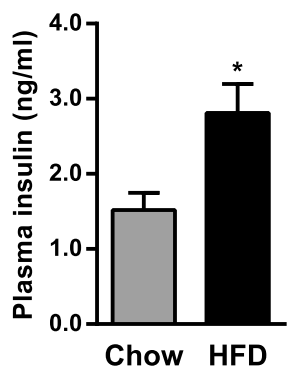

15M Irs2 $2^{--; A 7}$ adipose tissue

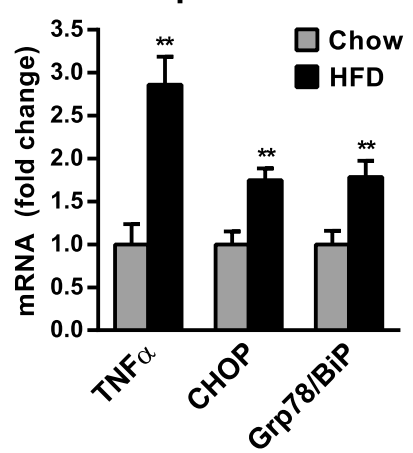

Fig. 6 (See legend on next page.) 


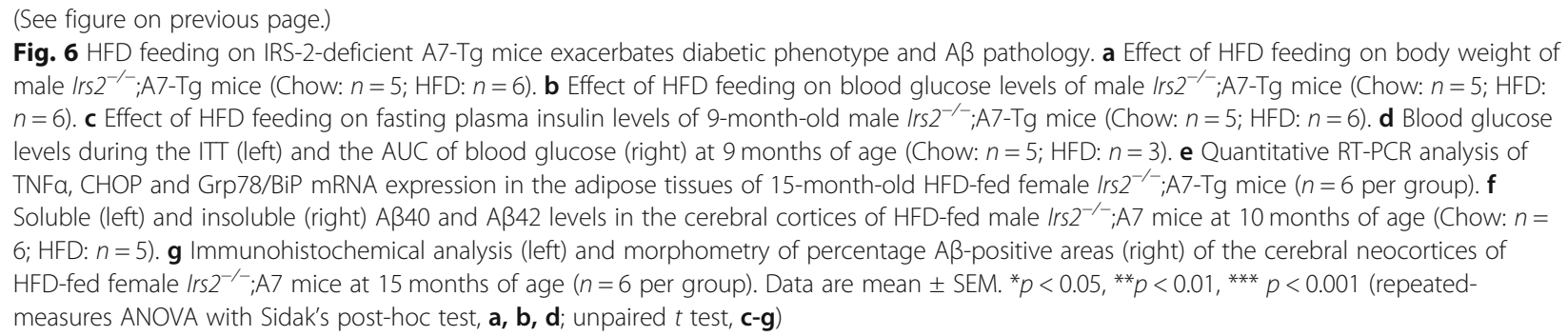

increase in body weight and blood glucose in $\operatorname{Irs} 2^{-1}$ ${ }^{-}$;A7-Tg mice (Additional file 6: Figure S6). HFD-induced metabolic stress was tested by quantitative RT-PCR analysis of adipose tissue from the 15-month-old mice. Notably, HFD feeding increased mRNA levels of TNF $\alpha$, Grp78/BiP and CHOP in Irs $2^{-/-}$;A7-Tg mice (Fig. 6e).

Finally, we analyzed the effects of HFD on A $\beta$ pathology of these mice. In the cerebral cortices of 10 -month-old Irs $2^{-/}$;A7-Tg mice, HFD feeding increased the levels of soluble $A \beta 40$ and $A \beta 42$ (Fig. 6f). At this age, insoluble $A \beta 40$ was significantly increased and insoluble $\mathrm{A} \beta 42$ also showed a trend of increase $(p=$ 0.059) in HFD-fed Irs $2^{-/}$;A7-Tg cortices (Fig. 6f). Immunohistochemical analysis revealed that amyloid deposition, which was suppressed in $\operatorname{Irs} 2^{-/-} ; \mathrm{A} 7-\mathrm{Tg}$ compared with A7-Tg mice, was significantly enhanced in the cerebral neocortices of HFD-fed $\operatorname{Irs} 2^{-1-}$; A7-Tg mice at 15 months of age (Fig. 6g). Altogether, HFD feeding of mice deficient in IRS-2 enhanced systemic inflammation and ER stress, exacerbated metabolic abnormalities, and promoted $A \beta$ accumulation in the brain. These observations further support the direct role of diet-induced metabolic stress, the underpinnings of insulin resistance, in the induction and aggravation of AD-like $A \beta$ pathology in the brain, irrespective of reduced insulin action per se.

\section{Discussion}

The pathophysiological link between T2DM and AD is receiving increasing attention. Previous studies have suggested a possible involvement of insulin resistance, a core feature of T2DM, in the exacerbation of cognitive decline and pathology of $\mathrm{AD}[8,16,17]$. In this study, we have addressed the questions on the chronological changes, causal relationships, and the molecular mechanisms of insulin resistance and amyloid pathology in a mouse model of $\mathrm{AD}$ with metabolic and genetic interventions.

In this study using A7-Tg mice, increased plasma insulin and blood glucose levels were observed as early as 2 months after initiation of HFD feeding on 3-month-old A7-Tg mice. In these mice, insulin-induced tyrosine phosphorylation of IR in the brain was suppressed compared to that in chow-fed mice (Fig. 1e). Defective brain insulin response was still evident in 9-month-old HFD-fed A7-Tg mice (Fig. 1f), indicating that chronic HFD exposure led to impaired insulin signaling both in the periphery and in the brain.

"Brain insulin resistance" could be due to either impaired response of brain cells to the extracellular insulin or disrupted transport of insulin to the brain [22]. Impaired response of brain cells was suggested by insulin stimulation assays of the brain tissues in vitro $[8,39]$. With regard to the brain entry of insulin, the effect of metabolic overload on the insulin transport from blood to the brain parenchyma has remained unclear. We demonstrated that the ISF/plasma insulin ratio during the hyperinsulinemic clamp was reduced in HFD-fed A7-Tg mice (Fig. 1j). Decreased ratio of insulin in the cerebrospinal fluid (CSF) to plasma has previously been shown in insulin resistant conditions in humans and dogs [40-42], although it remains elusive if the changes in CSF recapitulate that in brain ISF. A few attempts to directly measure ISF insulin in the rat hypothalamus using the microdialysis technique showed that a meal or peripheral insulin infusion affected the levels of hypothalamic ISF insulin [43, 44]. It has also been shown in APP transgenic mice that an acute and modest elevation of the levels of peripheral insulin has no effect on the levels of ISF insulin [45]. However, it remained unknown whether the ISF insulin levels are altered under metabolic abnormalities within brain areas affected in AD, e.g., hippocampus and cerebral neocortices. Although multiple physiological processes other than insulin action might have been affected during the hyperinsulinemic clamp, and the quantitation of the basal ISF insulin levels should have enabled a more precise determination of the changes in brain insulin transport, our current observations under the condition of hyperinsulinemic clamp support the hypothesis that defective insulin transport to the brain might be one of the underlying mechanisms of diet-induced brain insulin resistance. Similar mechanisms have been suggested in the skeletal muscle, where HFD-induced impairment of insulin signaling in the endothelial cells contributed to the delayed insulin delivery to the interstitial space [46]. Whether impairment in insulin signaling in brain vessels 
contributes to the HFD-induced reduction in insulin transport to the brain should further be examined.

Time-course analyses in HFD-fed A7-Tg mice showed no changes in the levels of brain $A \beta$ at 5 months of age when diet-induced insulin resistance was already observed, which was followed by increases in soluble and insoluble $A \beta$ at 9 months of age (Fig. 2). These results suggested that the development of insulin resistance precedes that of $A \beta$ accumulation. We therefore regarded the age of 9 months as the critical period of HFD-accelerated amyloid deposition in our A7-Tg model mice, when biochemical levels of brain $A \beta$, but not $A \beta$ deposition, started to increase.

In view of the potential application of dietary interventions as therapeutic/preventive strategies for $\mathrm{AD}$, it is critical to know whether T2DM-induced exacerbation of $\mathrm{AD}$ pathology is a reversible process. We therefore explored the efficacy of dietary interventions starting at a defined pathological stage of amyloid pathology in HFD-fed A7-Tg mice. Previously, caloric restriction and diet switching after HFD feeding have been shown to reduce amyloid deposition in AD model mice [36, 37, 47, 48]. In the current study, we systematically examined the effect of dietary interventions after the onset of HFD-induced insulin resistance and an increase in brain insoluble $A \beta$. Feeding the HFD followed by the chow diet significantly suppressed the effects of HFD feeding on insulin resistance and $A \beta$ deposition, and HFD feeding followed by CR had more pronounced effects (Fig. 4). Altogether, these results suggested the positive and reversible correlation between the diet-induced peripheral/brain insulin resistance and brain amyloid pathology during the early stages of AD pathophysiology. The association between T2DM and amyloid pathology has been supported by studies focusing on the effects of insulin resistance in the late middle-aged population (45-64 years old) [18], with lesser effects in older population [49]. Thus, components of T2DM, e.g., insulin resistance, might affect the rate of $A \beta$ deposition during the very early, preclinical stage of $\mathrm{AD}$, which dovetails with our observation in our AD model mice that recapitulate the early stage of AD pathophysiology.

Previous studies in multiple AD mouse models have altogether shown the exacerbation of amyloid pathology by diet-induced metabolic abnormalities. In some models, changes in enzymes responsible for either $A \beta$ degradation (IDE, neprilysin) or production (secretases) have been documented $[19,47,50]$. However, the mechanisms of increase in $A \beta$ deposition were not consistently elucidated, and changes in the $A \beta$-related enzymes or APP fragments were not detected in our present study. We have for the first time examined the in vivo dynamics of brain ISF $A \beta$ under HFD feeding using the brain microdialysis, and found that HFD feeding significantly extended the half-life of ISF $\mathrm{A} \beta$ in $\mathrm{A} 7-\mathrm{Tg}$ mice of 9-months-old, a critical age for $\mathrm{A} \beta$ accumulation (Fig. 3k). It has been suggested that the levels and the half-life of ISF $A \beta$ might be affected by the presence of amyloid plaques in aged AD model mice [30,51]; however, we might have minimized such an effect of insoluble $A \beta$ pools that could affect the equilibrium with ISF $A \beta$ in the plaque-free 9-month-old A7-Tg brains. No differences in ISF $A \beta$ levels and clearance at 5 months of age was consistent with the lack of changes in $A \beta$ levels by biochemical analysis (Fig. $3 g$ ), supporting the idea that decreased $\mathrm{A} \beta$ clearance that become evident by 9 months of age contributed to the accelerated amyloid pathology in the brains of our HFD-fed mice. In addition to the proteolytic digestion, the involvement of glial and vascular factors has been implicated in the clearance mechanisms of $A \beta[52,53]$. Further study is needed to elucidate the molecular mechanism of diet-induced reduction in $\mathrm{A} \beta$ clearance.

Although a series of experiments in HFD-fed A7-Tg mice has suggested the causal relationship between insulin resistance and amyloid pathology, it is difficult to discriminate the effects of individual changes associated with diet-induced insulin resistance, e.g., hyperinsulinemia, hyperglycemia and reduced insulin action, on the $A \beta$ pathology. To address this issue, we examined IRS-2-deficient A7- $\mathrm{Tg}$ mice as an alternative "insulin-resistant" mouse model. $\operatorname{Irs} 2^{-/-}$mice develop T2DM-like systemic phenotypes due to the reduced insulin action primarily in the liver and pancreatic $\beta$ cells $[28,54]$. IRS-2 expressed in the brain has been shown to play important roles in the regulation of food intake and peripheral insulin sensitivity, and could therefore be attributed to the development of diabetic phenotypes of Irs $2^{-/-}$mice [55]. Despite the pro-diabetic nature of the IRS-2 deletion, brains of $\operatorname{Irs} 2^{-/-} ; \mathrm{A} 7-\mathrm{Tg}$ mice accumulated lesser amount of amyloid plaques compared to that of $\mathrm{A} 7-\mathrm{Tg}$ mice (Fig. 5e), consistent with the earlier studies in Tg2576 mice lacking IRS-2 [23, 24], as well as in genetic disruption of neuronal insulin receptor [56] or IGF-1R $[23,26]$. One possible mechanism underlying these alleviated phenotypes on amyloid deposition might be linked to the beneficial properties of reduced insulin/ IGF-1 signaling for longevity, which have been extensively studied in a variety of organisms [57]. In contrast, insulin has been shown to increase the $A \beta$ levels in cell culture studies $[58,59]$. Overall, these lines of evidence suggest a suppressive role of reduced insulin signaling in $A \beta$ accumulation. Another possible mechanism of the anti-amyloidgenic effect of Irs 2 deletion could be due to a compensatory activation of the other downstream pathway, i.e., IRS-1 signaling axis, although the functional diversity of signaling pathways via IRS-1 and IRS-2 in brains has 
not been fully characterized. Future experiments should reveal the specific changes in the downstream signaling of each IRS protein in the brains of $\operatorname{Irs} 2^{-1}$ -;A7-Tg mice.

Given the paradoxical results of the two independent "insulin resistant" AD mouse models, an important problem emerges whether the defective insulin signaling pathway is causative to the reduced amyloid pathology. To gain insights into the interplay between the genetically induced reduction in insulin signaling and metabolic stress, we have loaded HFD on Irs $2^{-/} ; \mathrm{A} 7-\mathrm{Tg}$ mice and found an accelerating effect on amyloid accumulation in brains (Fig. $6 \mathrm{f}$ and g). The adverse effect of diet overloading on the development of insulin resistance was cumulative and not cancelled by IRS- 2 deficiency. These findings led us to speculate that the diet-induced insulin resistance and its upstream causes, but not the reduced insulin action per se, is the mechanism accelerating the amyloid pathophysiology in vivo.

Among the known upstream events of impaired insulin signaling in metabolic overload or T2DM, we observed that the degrees of inflammation and ER stress signaling in adipose tissue were significantly elevated by HFD feeding (Fig. 5f). IRS-2-deficient A7-Tg mice developed diabetic phenotype without causing the elevation of inflammatory/stress responses, whereas HFD feeding increased the activity of these signaling pathways (Fig. 6e). Inflammation and ER stress are known to be key to the cause of insulin resistance [60], and recent studies have shown that the upregulation of inflammation and ER stress in the hypothalamus also contributes to the obesity-associated insulin resistance [61]. These inflammation and ER stress pathways have been implicated in the pathogenesis of AD as well [62]. Further study is needed to unravel the possible involvement of the diet-induced inflammatory and stress signaling in brains in the diet-induced exacerbation of amyloid pathophysiology.

\section{Conclusions}

Our results suggest that diet-dependent, but not genetically-induced, insulin resistant states were causally and reversibly correlated with brain $A \beta$ metabolism and amyloid formation during the early pathological stages of AD. These observations raise the possibility that the causal factors of insulin resistance, e.g., diet-induced metabolic stress, but not the impaired insulin signaling per se, might be directly involved in the induction of exacerbated amyloid pathology in the brain. Although strategies improving the insulin signal activity, e.g. intranasal insulin administration and insulin resistance ameliorating agents, are currently under clinical trials, our study underscores the early intervention into diet-induced metabolic abnormalities as promising preventive, disease-modifying therapeutic strategies against $\mathrm{AD}$.

\section{Additional file}

\begin{abstract}
Additional file 1: Figure S1. Long-term exposure to HFD induces obesity, insulin resistance and hyperglycemia in A7-Tg mice. a Experimental scheme. A7-Tg mice were fed with a chow diet or HFD from 3 months of age. $\mathbf{b}$ Blood glucose levels of wild type (WT) and A7-Tg mice during the ITT (left) and the AUC of blood glucose (right) at 3 months of age (WT: $n=12$; A7- $\operatorname{Tg} n=11$ ). c Monthly body weight changes of female A7-Tg mice (Chow: $n=10$; HFD: $n=8$ ). $\mathbf{d}$ Fasting blood glucose levels of 9-month-old female A7-Tg mice (Chow: $n=12$; HFD: $n=15$ ). e Blood glucose levels during the ITT and the AUC of blood glucose of 9-monthold female A7-Tg mice (Chow: $n=12$; HFD: $n=14$ ). $\mathbf{f}$ Fasting blood glucose levels of 18-month-old female A7-Tg mice (Chow: $n=11$; HFD: $n=$ 8). $\mathbf{g}$ Blood glucose levels during the ITT and the AUC of blood glucose of 18-month-old female A7-Tg mice (Chow: $n=11$; HFD: $n=8$ ). $\mathbf{h}$, i 9month-old male A7-Tg mice were intraperitoneally injected PBS or insulin and brain lysates were immunoprecipitaed with antibodies against IGF$1 R \beta$ (h) and IRS-2 (i) followed by immunoblotting with anti-phospho Tyr (upper). Relative levels of signal intensity are shown (lower, Chow-PBS: $n$ $=6$; Chow-insulin: $n=6$; HFD-PBS: $n=5$; HFD-insulin: $n=6$ ). Data are mean \pm SEM. ${ }^{*} p<0.05,{ }^{* *} p<0.01,{ }^{* * *} p<0.001$ (repeated-measures ANOVA with Sidak's post-hoc test, $\mathbf{b}, \mathbf{c}, \mathbf{e}, \mathbf{g}$; unpaired $t$ test, $\mathbf{b}, \mathbf{d}, \mathbf{e}, \mathbf{f}, \mathbf{g}$; two-way ANOVA with Tukey's post-hoc test, $\mathbf{h}, \mathbf{i})$. (DOCX $156 \mathrm{~kb}$ )
\end{abstract}

Additional file 2: Figure S2. HFD increases $A \beta$ levels in the hippocampi of $A 7-T g$ mice. Soluble $A \beta$ levels in the hippocampus of 9-month-old male A7-Tg mice (Chow: $n=12$; HFD: $n=11$ ). Data are mean \pm SEM. ${ }^{* *} p$ $<0.01$ (unpaired $t$ test). (DOCX $60 \mathrm{~kb}$ )

Additional file 3: Figure S3. HFD affects clearance of ISF A 3 . a, b The expression of APP, CTFa/ $\beta$, BACE1 ADAM10 and a-tubulin was detected by immunoblots of cerebrocortical lysates of 5 (a, Chow: $n=9$; HFD: $n=$ 10) and 9 (b, Chow: $n=12$; HFD: $n=11$ )-month-old A7-Tg mice (left). Relative levels of signal intensity are shown (right). $\mathbf{c}$ The expression of APP, sAPPtotal/a/ $\beta$ in lysates of 10-month-old acute brain slices of A7-Tg mice was detected by immunoblots and relative levels of signal intensity were measured (Chow: $n=8$; HFD: $n=9$ ). Data are mean \pm SEM. ${ }^{* *} p<$ 0.01 (unpaired $t$ test). (DOCX $105 \mathrm{~kb}$ )

Additional file 4: Figure S4. Caloric restriction improves insulin sensitivity and suppresses $A \beta$ pathology in A7-Tg mice. a Monthly body weight changes of A7-Tg mice (Chow: $n=8 ;(R: n=9$ ). $\mathbf{b}$ Fasting blood glucose levels of 15-month-old A7-Tg mice (Chow: $n=12$; CR: $n=11$ ). c Blood glucose levels during the ITT (left) and the AUC of blood glucose (right) at 15 months of age (Chow: $n=12 ; C R: n=11$ ). $\mathbf{d}$ Levels of phosphorylated IR in A7-Tg mice fed with chow or CR upon insulin treatment. A7-Tg mice were intraperitoneally injected with PBS or insulin and Triton X-100-soluble cortical lysates were immunoprecipitaed with an anti-IR antibody followed by immunoblotting with anti-phospho Tyr and anti-IR antibodies at 15 month of age. Relative levels of signal intensity of phospho:total IR are shown ( $n=6$ per group). Data are mean \pm SEM. ${ }^{*} p<$ $0.05,{ }^{* *} p<0.01,{ }^{* * *} p<0.001$ (repeated-measures ANOVA with Sidak's post-hoc test, a, c; two-way ANOVA with Tukey's post-hoc test, d; unpaired $t$ test, b, c). (DOCX $94 \mathrm{~kb}$ )

Additional file 5: Figure S5. Deletion of IRS-2 induces metabolic impairments without significant induction of inflammation and ER stress in adipose tissues of A7-Tg mice. Quantitative RT-PCR analysis of TNFa, Grp78/Bip and CHOP mRNA expression in the adipose tissues of 15month-old Irs2 ${ }^{+/+} ; A 7-T g$ mice $(n=5)$, HFD-fed Irs2 ${ }^{+/+} ; A 7-\operatorname{Tg}$ mice $(n=6)$ or Irs $2^{-1-} ;$ A7-Tg mice $(n=6)$. Data are mean \pm SEM. ${ }^{*} p<0.05,{ }^{* *} p<0.01$, *** $p<0.001$ (one-way ANOVA with Tukey's post-hoc test). (DOCX $70 \mathrm{~kb}$ )

Additional file 6: Figure S6. HFD feeding on IRS-2-deficient A7-Tg mice exacerbates diabetic phenotype. a Effect of HFD feeding on body weight of female Irs2 ${ }^{--} ; \mathrm{A} 7-\mathrm{Tg}$ mice ( $n=6$ per group). $\mathbf{b}$ Effect of HFD feeding on blood glucose levels of female Irs $2^{-1} ; \mathrm{A} 7-\operatorname{Tg}$ mice ( $n=6$ per group). Data are mean \pm SEM. ${ }^{*} p<0.05,{ }^{* *} p<0.01,{ }^{* * *} p<0.001$ (repeated-measures ANOVA with Sidak's post-hoc test). (DOCX 73 kb)

\section{Abbreviations}

AD: Alzheimer's disease; $A \beta$ : Amyloid- $\beta$ peptide; $C R$ : Caloric restriction; CSF: Cerebrospinal fluid; ER: Endoplasmic reticulum; HFD: High-fat diet; 
IDE: Insulin degrading enzyme; IR: Insulin receptor; IRS: Insulin receptor substrate; ISF: Interstitial fluid; MWCO: Molecular weight cut-off; T2DM: Type 2 diabetes mellitus

\section{Acknowledgements}

We thank Dr. J. R. Cirrito (Washington Univ.) for technical supports.

\section{Funding}

This work was supported by the Strategic Research Program for Brain Sciences (SRPBS) from Japan Agency for Medical Reserach and Development (AMED) under the Grant Number JP18dm0107056, SRPBS from the Ministry of Education, Culture, Sports, Science and Technology (MEXT) under the Grant Number 10036021, JSPS KAKENHI Grant Number 16 K15478, and the Japan Health Foundation.

\section{Availability of data and materials}

All raw data used and/or analyzed during the current study are available from the corresponding author on reasonable request.

\section{Authors' contributions}

TW, K. Yamaguchi, KM, TS, AM and T. Kubota performed and analyzed experiments. TH, K. Yamada and YM provided technical assistance. TW, NK, T. Kadowaki and TI conceived and designed the study. TW and TI wrote the paper. All authors read and approved the final manuscript.

\section{Ethics approval and consent to participate}

All animal experimental procedures were performed in accordance with the regulations of the University of Tokyo and were approved by the committee of the University of Tokyo Graduate School of Medicine.

\section{Consent for publication}

Not applicable.

\section{Competing interests}

The authors declare that they have no competing interests.

\section{Publisher's Note}

Springer Nature remains neutral with regard to jurisdictional claims in published maps and institutional affiliations.

\section{Author details}

'Department of Neuropathology, Graduate School of Medicine, The University of Tokyo, 7-3-1 Hongo, Bunkyo-ku, Tokyo 113-0033, Japan. ${ }^{2}$ Department of Innovative Dementia Prevention, Graduate School of Medicine, The University of Tokyo, Tokyo 113-0033, Japan. ${ }^{3}$ Laboratory for Intestinal Ecosystem, RIKEN Center for Integrative Medical Sciences, Kanagawa 230-0045, Japan. ${ }^{4}$ Department of Diabetes and Metabolic Diseases, Graduate School of Medicine, The University of Tokyo, Tokyo 113-8655, Japan. ${ }^{5}$ Department of Clinical Nutrition Therapy, The University of Tokyo, Tokyo 113-8655, Japan. ${ }^{6}$ Department of Prevention of Diabetes and Lifestyle-Related Diseases, Graduate School of Medicine, The University of Tokyo, Tokyo 113-8655, Japan. 'Department of Metabolism and Nutrition, Mizonokuchi Hospital, Faculty of Medicine, Teikyo University, Tokyo 213-8507, Japan.

Received: 16 October 2018 Accepted: 15 March 2019

Published online: 12 April 2019

\section{References}

1. Selkoe DJ, Hardy J. The amyloid hypothesis of Alzheimer's disease at 25 years. EMBO Mol Med. 2016;8:595-608.

2. Biessels GJ, Staekenborg S, Brunner E, Brayne C, Scheltens P. Risk of dementia in diabetes mellitus: a systematic review. Lancet Neurol. 2006;5: 64-74.

3. Gudala K, Bansal D, Schifano F, Bhansali A. Diabetes mellitus and risk of dementia: a meta-analysis of prospective observational studies. J Diabetes Investig. 2013;4:640-50.

4. De Felice FG, Ferreira ST. Inflammation, defective insulin signaling, and mitochondrial dysfunction as common molecular denominators connecting type 2 diabetes to Alzheimer disease. Diabetes. 2014;63:2262-72.
5. Samuel VT, Shulman GI. Mechanisms for insulin resistance: common threads and missing links. Cell. 2012;148:852-71.

6. Steen E, Terry BM, Rivera EJ, Cannon JL, Neely TR, Tavares R, et al. Impaired insulin and insulin-like growth factor expression and signaling mechanisms in Alzheimer's disease--is this type 3 diabetes? J Alzheimers Dis. 2005;7:63-80.

7. Bomfim TR, Forny-Germano L, Sathler LB, Brito-Moreira J, Houzel JC, Decker $\mathrm{H}$, et al. An anti-diabetes agent protects the mouse brain from defective insulin signaling caused by Alzheimer's disease-associated A oligomers. J Clin Invest. 2012;122:1339-53.

8. Talbot K, Wang H, Kazi H, Han L, Bakshi KP, Stucky A, et al. Demonstrated brain insulin resistance in Alzheimer's disease patients is associated with IGF-1 resistance, IRS-1 dysregulation, and cognitive decline. J Clin Invest. 2012;122:1316-38.

9. Brüning JC, Cautam D, Deborah J. Role of brain insulin receptor in control of body weight and reproduction. Science. 2000;289:2122-5.

10. Benedict C, Hallschmid M, Hatke A, Schultes B, Fehm HL, Born J, et al. Intranasal insulin improves memory in humans. Psychoneuroendocrinology. 2004;29:1326-34.

11. Kleinridders A, Ferris HA, Cai W, Kahn CR. Insulin action in brain regulates systemic metabolism and brain function. Diabetes. 2014;63:2232-43.

12. Cukierman T, Gerstein HC, Williamson JD. Cognitive decline and dementia in diabetes - systematic overview of prospective observational studies. Diabetologia. 2005:48:2460-9.

13. Novak V, Milberg W, Hao Y, Munshi M, Novak P, Galica A, et al. Enhancement of vasoreactivity and cognition by intranasal insulin in type 2 diabetes. Diabetes Care. 2014:37:751-9.

14. Craft S, Baker LD, Montine TJ, Minoshima S, Watson GS, Claxton A, et al. Intranasal insulin therapy for Alzheimer disease and amnestic mild cognitive impairment: a pilot clinical trial. Arch Neurol. 2012;69:29-38.

15. McNay EC, Recknagel AK. Brain insulin signaling: a key component of cognitive processes and a potential basis for cognitive impairment in type 2 diabetes. Neurobiol Learn Mem. 2011;96:432-42.

16. Schrijvers EMC, Witteman JCM, Sijbrands EJG, Hofman A, Koudstaal PJ, Breteler MMB. Insulin metabolism and the risk of Alzheimer disease: the Rotterdam study. Neurology. 2010;75:1982-7.

17. Matsuzaki T, Sasaki K, Tanizaki Y, Hata J, Fujimi K, Matsui Y, et al. Insulin resistance is associated with the pathology of Alzheimer disease. Neurology. 2010;75:764-70.

18. Willette AA, Johnson SC, Birdsill AC, Sager MA, Christian B, Baker LD, et al. Insulin resistance predicts brain amyloid deposition in late middle-aged adults. Alzheimers Dement. 2015;11:504-10.

19. Ho L, Qin W, Pompl PN, Xiang Z, Wang J, Zhao Z, et al. Diet-induced insulin resistance promotes amyloidosis in a transgenic mouse model of Alzheimer's disease. FASEB J. 2004;18:902-4.

20. Julien C, Tremblay C, Phivilay A, Berthiaume L, Émond V, Julien P, et al. High-fat diet aggravates amyloid-beta and tau pathologies in the 3xTg-AD mouse model. Neurobiol Aging. 2010;31:1516-31.

21. Fitz NF, Cronican A, Pham T, Fogg A, Fauq AH, Chapman R, et al. Liver X receptor agonist treatment ameliorates amyloid pathology and memory deficits caused by high-fat diet in APP23 mice. J Neurosci. 2010;30:6862-72.

22. Biessels GJ, Reagan LP. Hippocampal insulin resistance and cognitive dysfunction. Nat Rev Neurosci. 2015;16:660-71.

23. Freude S, Hettich MM, Schumann C, Stohr O, Koch L, Kohler C, et al. Neuronal IGF-1 resistance reduces $A \beta$ accumulation and protects against premature death in a model of Alzheimer's disease. FASEB J. 2009;23:3315-24.

24. Killick R, Scales G, Leroy K, Causevic M, Hooper C, Irvine EE, et al. Deletion of Irs2 reduces amyloid deposition and rescues behavioural deficits in APP transgenic mice. Biochem Biophys Res Commun. 2009;386:257-62.

25. Cohen E, Paulsson JF, Blinder P, Burstyn-Cohen T, Du D, Estepa G, et al. Reduced IGF-1 signaling delays age-associated proteotoxicity in mice. Cell. 2009;139:1157-69

26. Gontier G, George C, Chaker Z, Holzenberger M, Aid S. Blocking IGF signaling in adult neurons alleviates Alzheimer's disease pathology through amyloid- $\beta$ clearance. J Neurosci. 2015;35:11500-13.

27. Yamada K, Yabuki $C$, Seubert $P$, Schenk D, Hori Y, Ohtsuki S, et al. A immunotherapy: intracerebral sequestration of $A \beta$ by an anti-A $\beta$ monoclonal antibody 266 with high affinity to soluble A $\beta$. J Neurosci. 2009; 29:11393-8.

28. Kubota N, Tobe K, Terauchi Y, Eto K, Yamauchi T, Suzuki R, et al. Disruption of insulin receptor substrate 2 causes type 2 diabetes because of liver 
insulin resistance and lack of compensatory $\beta$-cell hyperplasia. Diabetes. 2000;49:1880-9.

29. Yamamoto K, Tanei Z, Hashimoto T, Wakabayashi T, Okuno H, Naka Y, et al. Chronic optogenetic activation augments A $\beta$ pathology in a mouse model of Alzheimer disease. Cell Rep. 2015;11:859-65.

30. Cirrito JR, May PC, O'Dell MA, Taylor JW, Parsadanian M, Cramer JW, et al. In vivo assessment of brain interstitial fluid with microdialysis reveals plaqueassociated changes in amyloid- $\beta$ metabolism and half-life. J Neurosci. 2003; 23:8844-53.

31. O'Brien PD, Hinder LM, Callaghan BC, Feldman EL. Neurological consequences of obesity. Lancet Neurol. 2017;16:465-77.

32. Takeda S, Sato N, Ikimura K, Nishino H, Rakugi H, Morishita R. Novel microdialysis method to assess neuropeptides and large molecules in freemoving mouse. Neuroscience. 2011;186:110-9.

33. Maesako M, Uemura K, Iwata A, Kubota M, Watanabe $K$, Uemura M, et al. Continuation of exercise is necessary to inhibit high fat diet-induced $\beta$ amyloid deposition and memory deficit in amyloid precursor protein transgenic mice. PLoS One. 2013;8:e72796.

34. Petrov D, Pedrós I, Artiach G, Sureda FX, Barroso E, Pallàs M, et al. High-fat diet-induced deregulation of hippocampal insulin signaling and mitochondrial homeostasis deficiences contribute to Alzheimer disease pathology in rodents. Biochim Biophys Acta. 2015;1852:1687-99.

35. Parekh PI, Petro AE, Tiller JM, Feinglos MN, Surwit RS. Reversal of dietinduced obesity and diabetes in C57BL/6J mice. Metabolism. 1998;47:1089-96.

36. Patel NV, Gordon MN, Connor KE, Good RA, Engelman RW, Mason J, et al. Caloric restriction attenuates $A \beta$-deposition in Alzheimer transgenic models. Neurobiol Aging. 2005;26:995-1000.

37. Wang J, Ho L, Qin W, Rocher AB, Seror I, Humala N, et al. Caloric restriction attenuates $\beta$-amyloid neuropathology in a mouse model of Alzheimer's disease. FASEB J. 2005;19:659-61.

38. Wellen KE, Hotamisligil GS. Inflammation, stress, and diabetes. J Clin Invest. 2005:115:1111-9.

39. Mielke JG, Taghibiglou C, Liu L, Zhang Y, Jia Z, Adeli K, et al. A biochemical and functional characterization of diet-induced brain insulin resistance. Neurochem. 2005;93:1568-78.

40. Kaiyala K, Prigeon R, Kahn S. Obesity induced by a high-fat diet is associated with reduced brain insulin transport in dogs. Diabetes. 2000:1525-33.

41. Kern W, Benedict C, Schultes B, Plohr F, Moser A, Born J, et al. Low cerebrospinal fluid insulin levels in obese humans. Diabetologia. 2006;49: 2790-2.

42. Heni M, Schöpfer P, Peter A, Sartorius T, Fritsche A, Synofzik M, et al. Evidence for altered transport of insulin across the blood-brain barrier in insulin-resistant humans. Acta Diabetol. 2014;51:679-81.

43. Orosco M, Gerozissis K, Rouch C, Nicolaïdis S. Feeding-related immunoreactive insulin changes in the PVN-VMH revealed by microdialysis. Brain Res. 1995;671:149-58.

44. Gerozissis K, Orosco M, Rouch C, Nicolaidis S. Insulin responses to a fat meal in hypothalamic microdialysates and plasma. Physiol Behav. 1997;62:767-72.

45. Stanley M, Macauley SL, Caesar EE, Koscal L, Moritz W, Robinson GO, et al. The effects of peripheral and central high insulin on brain insulin signaling and amyloid- $\beta$ in young and old APP/PS1 mice. J Neurosci. 2016;36:11704-15.

46. Kubota T, Kubota N, Kumagai H, Yamaguchi S, Kozono H, Takahashi T, et al. Impaired insulin signaling in endothelial cells reduces insulin-induced glucose uptake by skeletal muscle. Cell Metab. 2011;13:294-307.

47. Maesako M, Uemura K, Kubota M, Kuzuya A, Sasaki K, Hayashida N, et al. Exercise is more effective than diet control in preventing high fat dietinduced $\beta$-amyloid deposition and memory deficit in amyloid precursor protein transgenic mice. J Biol Chem. 2012;287:23024-33.

48. Walker JM, Dixit S, Saulsberry AC, May JM, Harrison FE. Reversal of high fat diet-induced obesity improves glucose tolerance, inflammatory response, $\beta$ amyloid accumulation and cognitive decline in the APP/PSEN1 mouse model of Alzheimer's disease. Neurobiol Dis. 2017;100:87-98.

49. Pruzin JJ, Nelson PT, Abner EL, Arvanitakis Z. Invited review: relationship of type 2 diabetes to human brain pathology. Neuropathol Appl Neurobiol. 2018:1-16.

50. Ettcheto M, Petrov D, Pedrós I, Alva N, Carbonell T, Beas-Zarate C, Pallas M, Auladell C, Folch JCA. Evaluation of neuropathological effects of a high-fat diet in a presymptomatic Alzheimer's disease stage in APP/PS1 mice. J Alzheimers Dis. 2016;54:233-51.

51. Hong S, Quintero-Monzon O, Ostaszewski BL, Podlisny DR, Cavanaugh WT, Yang $T$, et al. Dynamic analysis of amyloid $\beta$-protein in behaving mice reveals opposing changes in ISF versus parenchymal A $\beta$ during age-related plaque formation. J Neurosci. 2011;31:15861-9.

52. Ries M, Sastre M. Mechanisms of A $\beta$ clearance and degradation by glial cells. Front Aging Neurosci. 2016;8:160.

53. Tarasoff-Conway JM, Carare RO, Osorio RS, Glodzik L, Butler T, Fieremans E, et al. Clearance systems in the brain-implications for Alzheimer disease. Nat Rev Neurol. 2015;11:457-70.

54. Withers DJ, Gutierrez JS, Towery H, Burks DJ, Ren JM, Previs S, et al. Disruption of IRS-2 causes type 2 diabetes in mice. Nature. 1998;391:900-4.

55. Taguchi A, Wartschow LM, White MF. Brain IRS2 signaling coordinates life span and nutrient homeostasis. Science. 2007:317:369-72.

56. Stöhr O, Schilbach K, Moll L, Hettich MM, Freude S, Wunderlich FT, et al. Insulin receptor signaling mediates APP processing and $\beta$-amyloid accumulation without altering survival in a transgenic mouse model of Alzheimer's disease. Age. 2013:35:83-101.

57. Fontana $L$, Partridge $L$, Longo VD. Extending healthy life span - from yeast to humans. Science. 2010;328:321-6.

58. Gasparini L, Gouras GK, Wang R, Gross RS, Beal MF, Greengard P, et al. Stimulation of $\beta$-amyloid precursor protein trafficking by insulin reduces intraneuronal $\beta$-amyloid and requires mitogen-activated protein kinase signaling. J Neurosci. 2001;21:2561-70.

59. Pandini G, Pace V, Copani A, Squatrito S, Milardi D, Vigneri R. Insulin has multiple antiamyloidogenic effects on human neuronal cells. Endocrinology. 2013;154:375-87.

60. Hotamisligil GS. Endoplasmic reticulum stress and the inflammatory basis of metabolic disease. Cell. 2010;140:900-17.

61. Jais A, Brüning JC, Jais A, Brüning JC. Hypothalamic inflammation in obesity and metabolic disease. J Clin Invest. 2017;127:24-32.

62. Salminen A, Kauppinen A, Suuronen T, Kaarniranta K, Ojala J. ER stress in Alzheimer's disease: a novel neuronal trigger for inflammation and Alzheimer's pathology. J Neuroinflammation. 2009;6:41.

\section{Ready to submit your research? Choose BMC and benefit from:}

- fast, convenient online submission

- thorough peer review by experienced researchers in your field

- rapid publication on acceptance

- support for research data, including large and complex data types

- gold Open Access which fosters wider collaboration and increased citations

- maximum visibility for your research: over $100 \mathrm{M}$ website views per year

At BMC, research is always in progress.

Learn more biomedcentral.com/submissions 